\title{
Nuclear iASPP may facilitate prostate cancer progression
}

\author{
EV Morris ${ }^{1,2}$, L Cerundolo ${ }^{1,2}$, M Lu$^{1}$, C Verrill ${ }^{3}$, F Fritzsche ${ }^{1}$, MJ White ${ }^{1}$, GN Thalmann ${ }^{4}$, CS ten Donkelaar ${ }^{1}$, I Ratnayaka ${ }^{1}$, V Salter ${ }^{1}$, \\ FC Hamdy ${ }^{2}, X L^{*, 1}$ and RJ Bryant ${ }^{*, 1,2}$
}

One of the major challenges in prostate cancer $(\mathrm{PCa})$ research is the identification of key players that control the progression of primary cancers to invasive and metastatic disease. The majority of metastatic PCa express wild-type p53, whereas loss of p63 expression, a p53 family member, is a common event. Here we identify inhibitor of apoptosis-stimulating protein of p53 (iASPP), a common cellular regulator of p53 and p63, as an important player of PCa progression. Detailed analysis of the prostate epithelium of iASPP transgenic mice, iASPP ${ }^{\Delta 8 / \Delta 8}$ mice, revealed that iASPP deficiency resulted in a reduction in the number of $p 63$ expressing basal epithelial cells compared with that seen in wild-type mice. Nuclear and cytoplasmic iASPP expression was greater in PCa samples compared with benign epithelium. Importantly nuclear iASPP associated with p53 accumulation in vitro and in vivo. A pair of isogenic primary and metastatic PCa cell lines revealed that nuclear iASPP is enriched in the highly metastatic PCa cells. Nuclear IASPP is often detected in PCa cells located at the invasive leading edge in vivo. Increased IASPP expression associated with metastatic disease and PCa-specific death in a clinical cohort with long-term follow-up. These results suggest that iASPP function is required to maintain the expression of p63 in normal basal prostate epithelium, and nuclear iASPP may inactivate p53 function and facilitate PCa progression. Thus iASPP expression may act as a predictive marker of PCa progression.

Cell Death and Disease (2014) 5, e1492; doi:10.1038/cddis.2014.442; published online 23 October 2014

Prostate cancer $(\mathrm{PCa})$ is the commonest male malignancy and second leading cause of male cancer-related death in the Western world. As metastatic PCa can kill patients it is important to understand the molecular switches responsible for progression of localised disease to an invasive and metastatic phenotype.

Mutation of the tumour suppressor gene p53, one of the commonest mutated genes in human cancers, ${ }^{1}$ is associated with invasive metastatic PCa. p53 mutation or loss-ofheterozygosity rates in early $\mathrm{PCa}$ are low, ${ }^{2-6}$ suggesting p53 mutation is a late event in $\mathrm{PCa}$ and that selection for loss of p53 function occurs during PCa progression. ${ }^{7-15}$ Mutant p53 can induce cancer cell invasion by binding to p63 and inhibiting its transcriptional activity. ${ }^{16-19}$ p63 is a member of the p53 family and shares high sequence similarity to $p 53$ at its DNA binding domain. p63 is predominantly expressed in basal epithelial cells and is a master transcription factor that determines epithelial stratification. There are six p63 isoforms and TAp63a, $\beta$ and $\gamma$ contain different lengths of $C$ terminus, whereas $\Delta N p 63 a, \Delta N p 63 \beta$ and $\Delta N p 63 \gamma$ lack the $\mathrm{N}$-terminal transactivation domain. p63 is expressed in the basal cells of normal adult prostate epithelium ${ }^{20}$ with $\Delta \mathrm{Np63a}$ being the most prominent isoform. ${ }^{21} \Delta$ Np63-positive cells of the urogenital sinus can generate all prostate epithelial cell lineages in mice, ${ }^{22}$ suggesting that these are stem/progenitor cells. Loss of the p63-expressing basal cell layer is a hallmark of invasive $\mathrm{PCa}{ }^{21,23,24}$ Mutant p53 is mainly detected in metastatic PCa cells, therefore it is unlikely that mutant p53 induces PCa cellular invasiveness by inhibiting p63 function. In addition, as p53 mutations or copy number loss are detected in only $25 \%{ }^{2}$ of metastatic PCa, it is likely that p53 loses its tumour suppressor function in metastatic disease through other means. Cellular regulators of p53 may be responsible for the inactivation of $\mathrm{p} 53$.

Increased expression of two p53 inhibitors, mouse double minute 2 homologue and inhibitor of apoptosis-stimulating protein of p53 (iASPP), is responsible for the inactivation of wild-type p53 in human malignant melanoma ${ }^{25}$ which, like $\mathrm{PCa}$, has a low rate of $\mathrm{p} 53$ mutation. iASPP belongs to the ASPP family of proteins that comprise iASPP, ASPP1 and ASPP2. ASPP1 and ASPP2 were originally identified as activators, and iASPP as an inhibitor, of p53-mediated

\footnotetext{
${ }^{1}$ Ludwig Institute for Cancer Research Ltd, University of Oxford, Nuffield Department of Clinical Medicine, Old Road Campus Research Building (off Roosevelt Drive), Headington, Oxford, UK; ${ }^{2}$ Nuffield Department of Surgical Sciences, University of Oxford, Old Road Campus Research Building (off Roosevelt Drive), Headington, Oxford, UK; ${ }^{3}$ Department of Cellular Pathology and NIHR Oxford Biomedical Research Centre, Oxford University Hospitals NHS Trust, John Radcliffe Hospital, Headley Way, Oxford, UK and ${ }^{4}$ Department of Urology, Inselspital, Bern, Switzerland

${ }^{*}$ Corresponding author: X Lu and RJ Bryant, Ludwig Institute for Cancer Research Ltd, University of Oxford, Nuffield Department of Clinical Medicine, Old Road Campus Research Building (off Roosevelt Drive), Headington, Oxford OX37DQ, UK. Tel: +44 01865 617507; Fax: +44 01865 768876; E-mail: xin.lu@ludwig.ox.ac.uk or richard. bryant@nds.ox.ac.uk

Abbreviations: BrdU, bromodeoxyuridine; BSA, bovine serum albumin; DAPI, 4',6-diamidino-2-phenylindole; DMEM, Dulbecco's Modified Eagle Medium; EDTA, ethylenediaminetetraacetic acid; EMT, epithelial-to-mesenchymal transition; FCS, Fetal calf serum; H\&E, haematoxylin and eosin; HRP, horseradish peroxidase; iASPP, inhibitor of apoptosis-stimulating protein of p53; IF, immunofluorescence; IHC, immunohistochemistry; NET, $100 \mathrm{mM} \mathrm{NaCl,} 1 \mathrm{mM}$ EDTA, $20 \mathrm{mM}$ Tris; NHF, normal human fibroblast; PBS, phosphate buffered saline; PCa, prostate cancer; pT3, pathologic tumour stage 3; SDS, sodium dodecyl sulfate; TMA, tissue microarray; WB, western blotting

Received 16.6.14; revised 11.8.14; accepted 25.8.14; Edited by R Johnstone
} 
apoptosis. $^{26,27}$ Studies have demonstrated that ASPP2 is a haploinsufficient tumour suppressor, ${ }^{28-30}$ and ASPP1 and ASPP2 cooperate with oncogenic RAS to potentiate RAS signalling. ${ }^{31-33}$ ASPP2 can exert its tumour suppressor function by mediating RAS-induced cellular senescence and by inhibiting RAS-induced autophagy in primary cells. ${ }^{31,33}$ ASPP2 also increases RAS-induced p53-mediated transcription and apoptosis in cancer cells. ${ }^{32}$ In normal epithelial cells, ASPP2 can bind and colocalise with protease activated receptor 3 thereby maintaining the integrity of cell polarity and adherence junctions. ${ }^{34,35}$ ASPP2 is a novel suppressor of squamous cell carcinoma through its ability to repress $\Delta \mathrm{Np} 63$ expression via a nuclear factor kappa-light-chain-enhancer of activated B cells-mediated pathway. ${ }^{30}$ iASPP is thought to function as an oncoprotein as it is over-expressed in several malignancies ${ }^{36-39}$ including a small cohort of PCa cases. ${ }^{40}$ Consistent with this, iASPP is highly expressed in basal epithelial cells and its expression level decreases upon cellular differentiation in vitro and in vivo. ${ }^{30,41}$ iASPP is an inhibitor of cellular senescence and iASPP deficiency accelerates differentiation of keratinocytes in vitro and in vivo, partly through iASPP's ability to bind and regulate p63 function. ${ }^{41,42}$
These observations are in agreement with in vivo findings that IASPP and ASPP2 are key regulators of epithelial stratification with opposing functions, partly through their ability to exert opposing regulation of p63 expression and activity. ${ }^{30,41,42} \mathrm{We}$ recently showed that ASPP2 represses $\triangle \mathrm{Np63}$ expression ${ }^{30}$ whilst iASPP is known to induce p63 expression in keratinocytes, ${ }^{42}$ and we also showed that iASPP binds p63 and regulates its transcriptional activity to suppress cellular senescence and differentiation. ${ }^{41}$ Since p63 is required for mouse prostate development and its expression is lost in invasive PCa, we investigated whether iASPP plays a role in mouse prostate development through its ability to regulate $\mathrm{p} 63$. The potential role of iASPP in regulating the behaviour of p63-negative PCa cells was also investigated in PCa samples.

\section{Results}

iASPP deficiency causes a reduced number of p63-expressing basal cells and increased expression of differentiation markers. To investigate the effect of iASPP
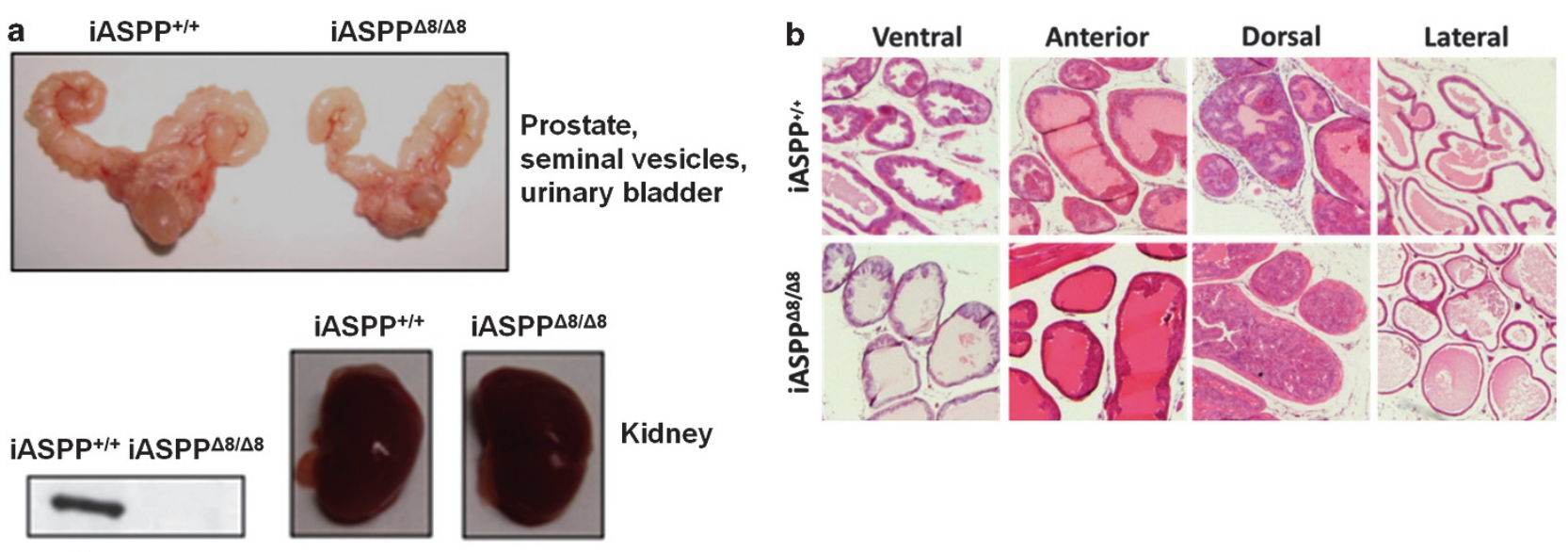

Kidney
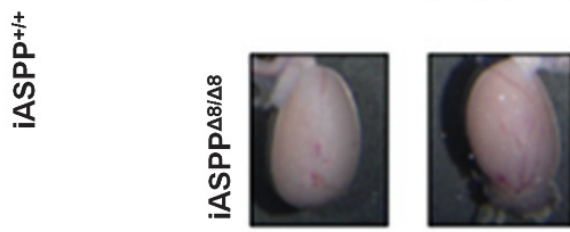

Testis
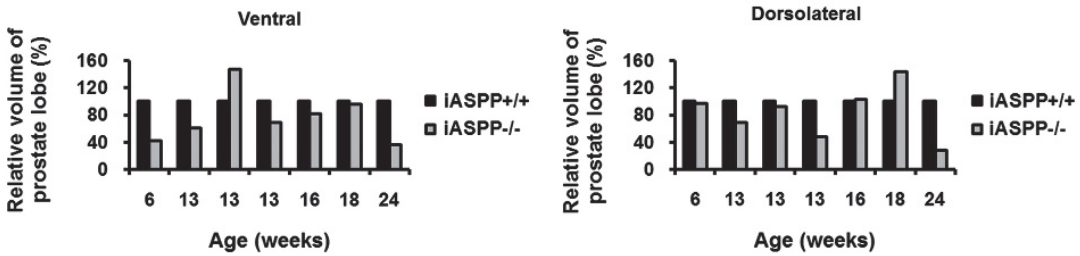

Figure 1 Phenotypic analysis of iASPP ${ }^{\Delta 8 / \Delta 8}$ mouse prostates. (a) The prostate glands of iASPP ${ }^{\Delta 8 / \Delta 8}$ mice were macroscopically similar to those of wild-type mice. (b) iASPP ${ }^{\Delta 8 / \Delta 8}$ mouse prostate lobes developed with an intact epithelial lining and a lumen. (c) iASPP ${ }^{\Delta 8 / \Delta 8}$ mouse $(n=3)$ prostate lobes demonstrated a small reduction in the number of Ki67-positive actively proliferating epithelial cells compared with $\mathrm{iASPP}^{+/+}(n=3)$ controls. (d) $\operatorname{iASPP}^{\Delta 8 / \Delta 8}(n=4)$ mice demonstrated a small reduction in the number of BrdU-labelled cells in each lobe of the prostate following BrdU injection compared with iASPP ${ }^{+/+}(n=3)$ controls. (e) iASPP ${ }^{\Delta 8 / \Delta 8}$ mice $(n=5)$ demonstrated a small reduction in the number of TUNEL-positive apoptotic epithelial cells in each lobe of the prostate compared with iASPP ${ }^{+/+}(n=5)$ controls. (f) iASPP ${ }^{\Delta 8 / \Delta 8}$ mice $(n=5)$ had significantly fewer p63-positive basal epithelial cells compared with iASPP ${ }^{+/+}$mice $(n=5)$. The expression level of TP63 in prostate protein extracts from iASPP ${ }^{\Delta 8 / \Delta 8}$ mice was diminished compared with iASPP ${ }^{+/+}$controls 
C

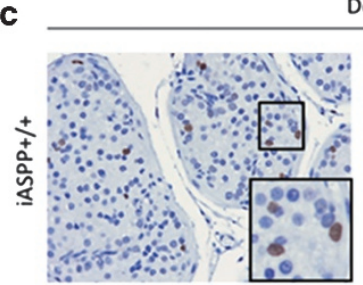

Dorsal

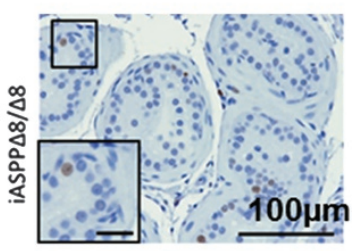

$50 \mu \mathrm{m}$

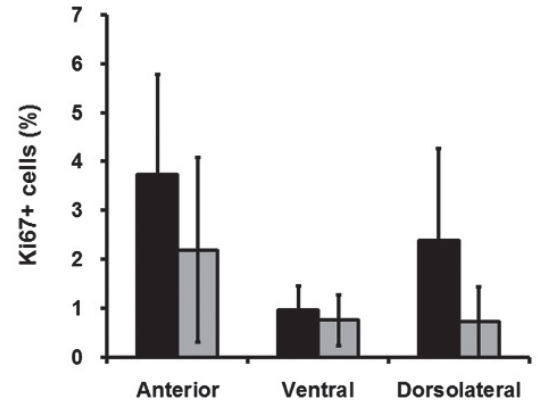

e

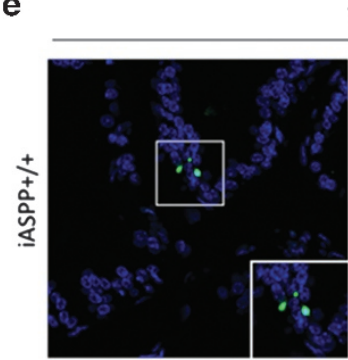

Ventral

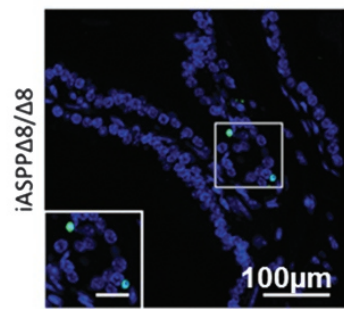

$50 \mu \mathrm{m}$

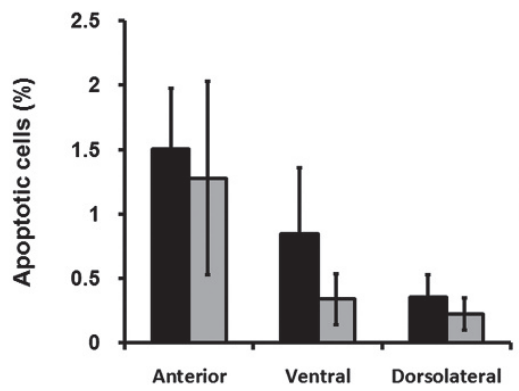

Figure 1

oss on gross prostate morphology the prostate glands from $\mathrm{iASPP}^{\Delta 8 / \Delta 8}$ mice were analysed macroscopically. The prostate gland lobes of $\mathrm{iASPP}^{\Delta 8 / \Delta 8}$ mice were sometimes smaller than those of age-matched wild-type mice but were not significantly smaller across the cohort $(P>0.05)$ (Figure 1a). There was no difference in overall size of these animals. The prostate lobes of $\mathrm{iASPP}^{\Delta 8 / \Delta 8}$ mice had an epithelial cell layer and a lumen with similar haematoxylin and eosin (H\&E) appearances to wild-type (Figure 1b). These results suggest that iASPP deficiency is unlikely to grossly affect mouse prostate development.

We showed previously that IASPP inhibits apoptosis and cellular senescence, therefore we tested whether iASPP d

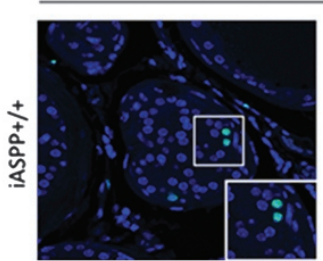

Dorsal

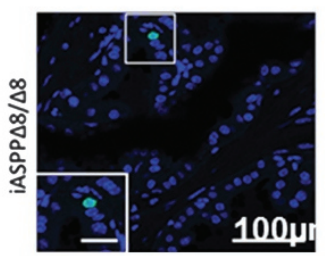

$50 \mu \mathrm{m}$

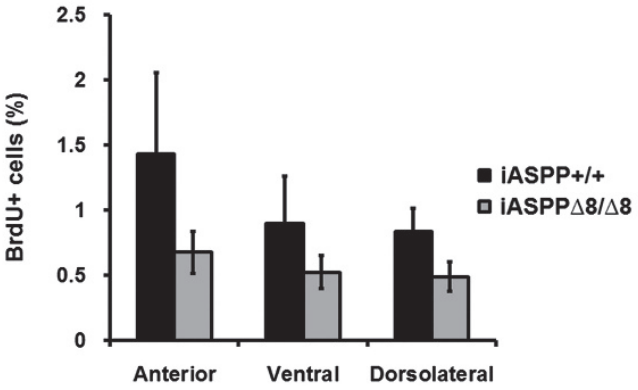

f
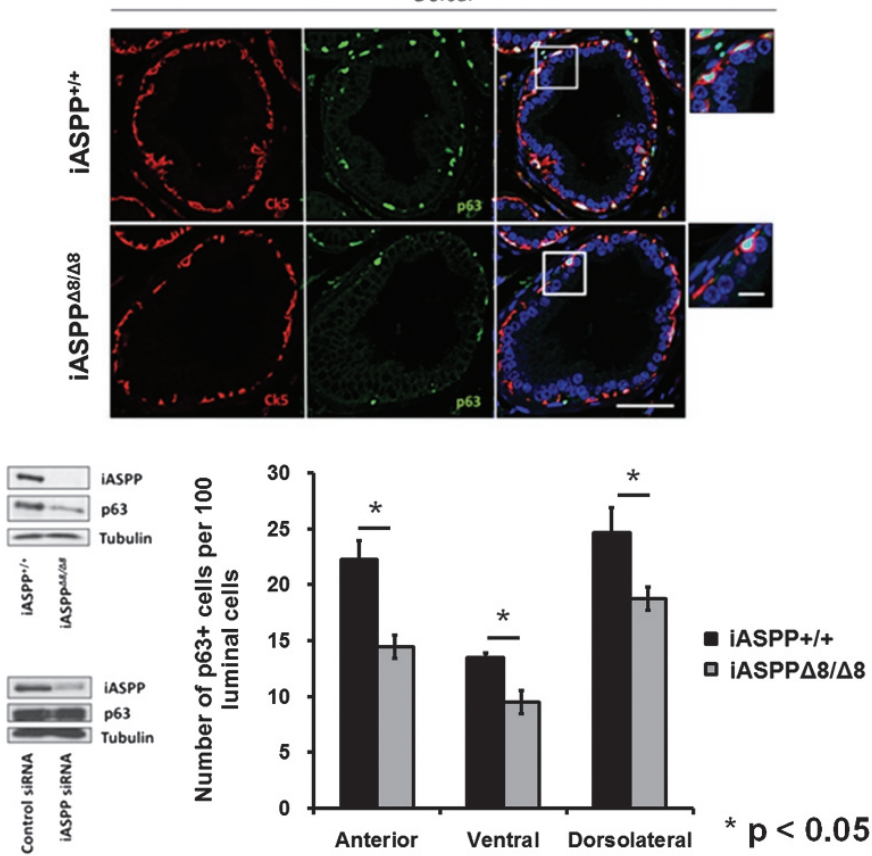

deficiency enhances apoptosis or inhibits cellular proliferation, and we observed a small reduction in the number of Ki67-expressing cells in $\mathrm{iASPP}^{\Delta 8 / \Delta 8}$ mice compared with wild-type (Figure 1c). iASPP ${ }^{\Delta 8 / \Delta 8}$ mice demonstrated a small reduction in the number of bromodeoxyuridine (BrdU)-labelled cells in all prostate lobes compared with wild-type (Figure 1d). Similar number of apoptotic prostate epithelial cells were observed in iASPP ${ }^{\Delta 8 / \Delta 8}$ mice compared with wild-type (Figure 1e). These results suggest that iASPP loss does not enhance apoptosis but reduces cellular proliferation in the mouse prostate.

iASPP has recently been found to be highly expressed in the nucleus of basal cells where it interacts with TP63, and its 
expression becomes cytoplasmic in differentiated cells. ${ }^{41,42}$ We observed that iASPP was expressed in both the TP63-positive basal cell layer and the TP63-negative luminal cell layer (Supplementary Figure 1A) of mouse prostate epithelium. Both cytoplasmic and nuclear iASPP expression accords with previous studies. ${ }^{43}$ The iASPP staining is specific and is confirmed by absence of signal in iASPP ${ }^{\Delta 8 / \Delta 8}$ mice (Supplementary Figure 1B). We observed a significant decrease in the number of p63-expressing epithelial cells in all lobes of iASPP ${ }^{\Delta 8 / \Delta 8}$ mouse prostates compared with wildtype (Figure 1f).

Since p63-expressing cells are progenitors and iASPP deficiency is known to facilitate keratinocyte differentiation, the effects of loss of iASPP function on prostate epithelial cell differentiation were investigated. The prostate mainly consists of basal and luminal cells, and a small subpopulation of neuroendocrine cells. ${ }^{44}$ Although the basal and luminal cells are discrete populations, intermediate cells express a mixture of basal and luminal markers ${ }^{45-48}$ and are thought to have entered the differentiation programme and be transitional between basal and luminal phenotypes. The cytokeratin (Ck) expression pattern can be used to distinguish between these three populations of cells. In prostate epithelium, basal cells express Ck5 and Ck14, luminal cells express Ck8 and Ck18 and intermediate cells express basal and luminal Cks and Ck19. Basal and luminal cells were present in iASPP-deficient mice as demonstrated by Ck5 and Ck8 IF (Supplementary Figure $1 \mathrm{C}$ ). To determine the levels of $\mathrm{Ck}$ expression, protein was extracted from prostate tissue from three iASPP ${ }^{\Delta 8 / \Delta 8}$ and three age-matched wild-type mice. We observed an increase in Ck19 expression in IASPP $^{\Delta 8 / \Delta 8}$ compared with wild-type prostate (Supplementary Figure 1D) with minimal changes in Ck5 and Ck8 expression. These results suggest that iASPP deficiency facilitates p63-expressing progenitors to commit to the luminal cell linage by transitioning into intermediate cells, and that iASPP regulates mouse prostate development through its ability to inhibit cellular senescence and prostate epithelium differentiation. The findings that iASPP is expressed in both basal and luminal prostate epithelial cells suggest that iASPP may affect prostate epithelial cell functions through p63-dependent and -independent pathways.

iASPP is expressed in human prostate epithelium and nuclear iASPP associates with invasive phenotypes. To investigate whether iASPP plays a role in human $\mathrm{PCa}$ we first examined iASPP expression pattern in a number of benign prostate samples using an anti-iASPP mouse monoclonal antibody LX049. ${ }^{41}$ to carry out IHC staining. We observed that iASPP was predominantly expressed in the nucleus and cytoplasm of p63-positive basal cells in benign prostate epithelium. Occasional low levels of iASPP expression were also observed in benign luminal epithelial cells a
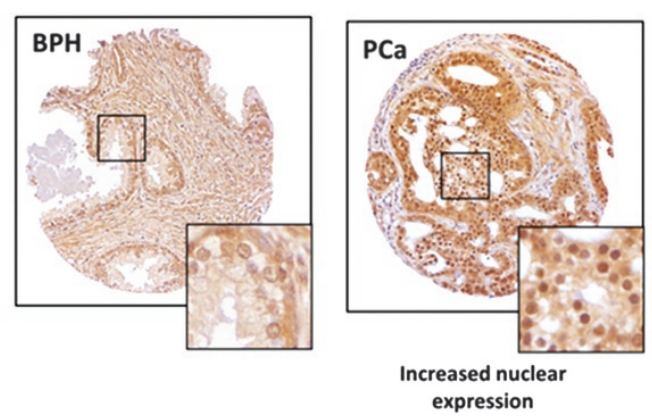

\begin{tabular}{|l|l|l|l|}
\hline $\begin{array}{l}\text { iASPP } \\
\text { expression }\end{array}$ & BPH & Cancer & P value \\
\hline Nuclear & $2 / 12$ & $129 / 202$ & 0.002 \\
\hline Cytoplasmic & $5 / 12$ & $156 / 202$ & 0.01 \\
\hline
\end{tabular}
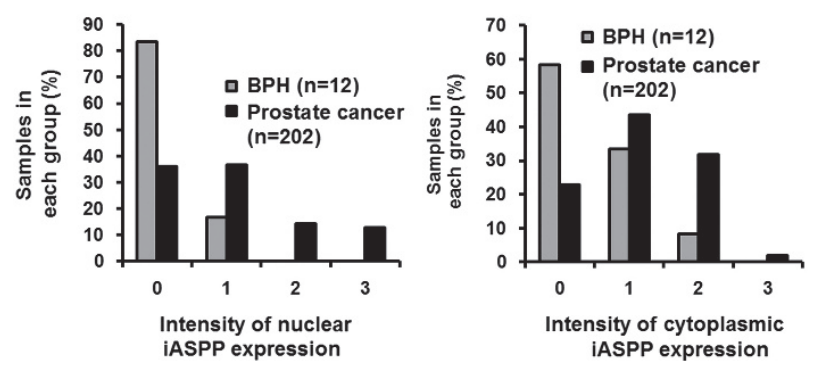

b
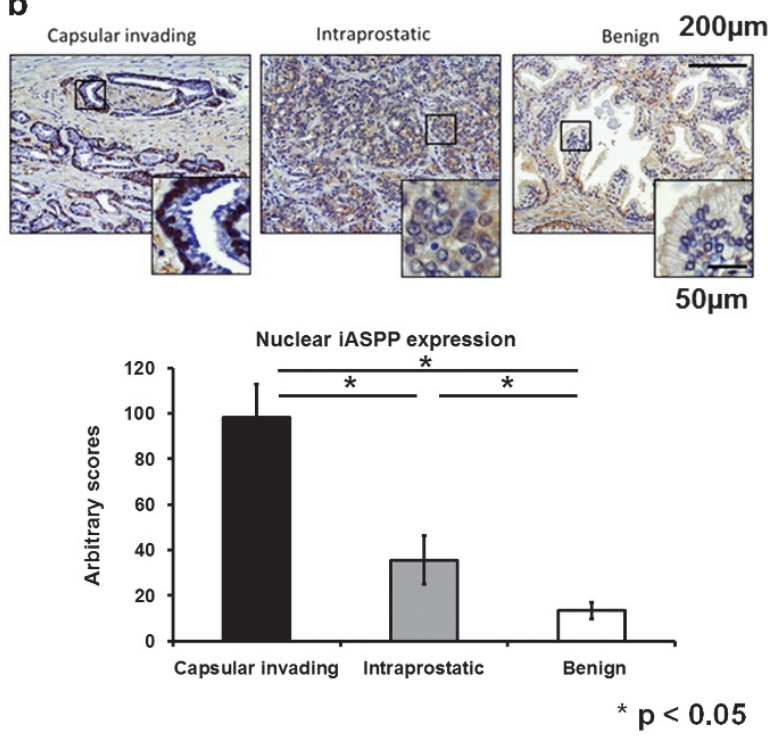

Figure 2 iASPP expression differs between benign and malignant human prostate epithelium. (a) iASPP is mainly expressed in the nucleus and cytoplasm of p63-positive basal cells, and to a lesser extent in the nucleus of luminal epithelial cells, in benign human prostate epithelium. Nuclear $(P=0.002)$ and cytoplasmic $(P=0.01)$ iASPP expression is increased in human prostate cancer samples compared with benign epithelial cell samples. (b) Nuclear iASPP expression was greater in prostate cancer cells invading through the capsule in locally invasive pT3a disease compared with areas of intra-prostatic tumour or benign prostate epithelium 
(Figure 2a). We noticed that the benign epithelium adjacent to areas of PCa expressed significantly greater levels of iASPP than benign prostate epithelium samples taken from men without PCa (Supplementary Figure 2A). Consistent with this an increase in both cytoplasmic and nuclear iASPP expression was observed in PCa samples in comparison to benign prostate epithelium (Figure 2a). By analysing iASPP expression in $\mathrm{PCa}$ cells with different invasive properties within locally advanced cases, we observed that nuclear (Figure 2b) and cytoplasmic (Supplementary Figure 2B) iASPP expression was significantly greater in cells at the 'leading edge' invading the prostate capsule compared with cancer cells within intra-prostatic tumour. These results suggest that iASPP expression patterns differ in PCa cells. High levels of nuclear and cytoplasmic iASPP associates with PCa cells with an invasive property, whereas low iASPP-expressing $\mathrm{PCa}$ cells are confined to the gland and are not invading locally.

Slow migrating nuclear iASPP is enriched in metastatic PCa cells. N-terminal phosphorylation of iASPP retards its migration in sodium dodecyl sulfate (SDS) gel and causes nuclear accumulation in cells, ${ }^{25}$ and nuclear iASPP localisation is associated with human melanoma metastasis. ${ }^{25}$ The observation that nuclear iASPP is enriched in PCa cells with invasive properties led us to test the hypothesis that iASPP phosphorylation may be enhanced in metastatic PCa cells in vitro using a pair of isogenic LNCaP cell lines. LNCaP-LN3 is a metastatic derivative of LNCaP cells. Using IF we observed that p53-null PC3 cells and p53-mutant (P233L and V274F) DU145 cells ${ }^{49}$ expressed predominantly cytoplasmic iASPP. In wild-type p53-expressing LNCaP cells, iASPP is expressed with a relatively equal distribution between nucleus and cytoplasm, whereas LNCaP-LN3 derivatives expressed predominantly nuclear iASPP (Figure 3a). iASPP migrated as two bands in WBs of these $\mathrm{PCa}$ cell lines however the proportion of slow-migrating iASPP was highest in LNCaP-LN3 cells corresponding with the enrichment of modified nuclear iASPP in these cells. LNCaP cells expressed both slow- and fast-migrating iASPP with similar intensity and this expression pattern correlates with the roughly equal cellular distribution of iASPP detected in these cells. PC3 and DU145 cells expressed predominantly fast-migrating unmodified cytoplasmic iASPP (Figure 3b). The slower migrating modified iASPP band is primarily detected in nuclear protein extracts, whereas the faster migrating unmodified iASPP band is localised primarily to the cytoplasm (Figure 3c). LNCaP-LN3 cells expressed a greater proportion of modified nuclear iASPP than LNCaP cells. These results illustrate that modified nuclear iASPP is enriched in PCa cells with high metastatic potential.

Increased nuclear iASPP expression correlates with TP53 accumulation in vivo and in organotypical co-cultures in vitro. p53 mutation is a late event in $\mathrm{PCa}$ progression. High levels of TP53 expression is often associated with p53 mutation and is detected in invasive metastatic PCa cells. In our tissue microarray (TMA) cohort of PCa samples we only detected high levels of TP53 expression ( $>30 \%$ of cancer cell nuclei ${ }^{14}$ ) in 5/200 PCa samples. We observed that nuclear iASPP expression was significantly higher in samples strongly expressing TP53 compared with samples with absent or weak TP53 expression (Figure 4a). High levels of TP53 expression were detected within cells at the 'leading edge' of locally invasive PCa compared with intraprostatic tumour cells. Higher levels of nuclear TP53 expression were detected in locally advanced PCa cases compared with organ-confined tumours (Figure 4b). These results suggest a potential association between high levels of TP53 and nuclear iASPP accumulation in the leading edge of locally invasive PCa.

This hypothesis was tested by performing an in vitro organotypic co-culture using DU145 cells known to harbour mutant $p 53^{49}$ and express high levels of TP53, which accumulates in the nucleus. Using double IF staining we observed that some DU145 cells with accumulated TP53 also expressed nuclear iASPP (Figure 4c). DU145 cells with colocalisation of iASPP and TP53 were preferentially seen at the 'leading edge' of the layer of cells within the organotypic cocultures. This contrasts with observations in organotypic cocultures of PC3 cells which do not express TP53, and LNCaP and LNCaP-LN3 cells expressing wild-type TP53. The association between nuclear TP53 and nuclear iASPP accumulation in organotypical co-cultures of DU145 cells suggests that mutant TP53 may interact with nuclear iASPP. Using an immunoprecipitation assay we observed that an anti-iASPP antibody was able to co-immuno-precipitate TP53 with iASPP in DU145 cell lysates (Figure $4 d$ ). These results suggest an association between the accumulation of mutant TP53 and nuclear iASPP, and that mutant TP53 is able to bind iASPP in vitro.

Increased iASPP expression in PCa is associated with an adverse clinical outcome. We investigated whether the increased iASPP expression observed in PCa samples might have prognostic clinical significance using a TMA of samples from 203 patients undergoing radical prostatectomy with prolonged clinical follow-up ${ }^{50}$ (Table 1). Increased iASPP expression was associated with an adverse clinical outcome. Increased nuclear iASPP expression in intermediate grade (Gleason sum score 7) PCa was significantly associated with PCa-specific death. Increased cytoplasmic iASPP expression in high grade (Gleason sum score $\geq 8$ ) PCa was associated with both metastasis formation and $\mathrm{PCa}$-specific death (Figure 5a). The prognostic significance of tumour stage, pre-operative prostate-specific antigen level, and nuclear and cytoplasmic iASPP expression were tested in a Cox regression multivariate analysis (Table 2). Nuclear iASPP expression in Gleason 7 tumours was prognostic for PCa-specific death, whilst cytoplasmic iASPP in high-grade (Gleason $\geq 8$ ) tumours was prognostic for the development of bone metastases and PCa-specific death.

Increased nuclear iASPP expression was associated with an increased risk of $\mathrm{PCa}$-specific death in patients with locally advanced $\mathrm{PCa}$ undergoing radical prostatectomy, whereas this association was not seen in organ-confined disease (Figure 5b). These results suggest that increased expression of nuclear and cytoplasmic iASPP has clinical significance by conferring an increased risk of developing metastases or resultant $\mathrm{PCa}$-specific death following treatment of early disease. 
a
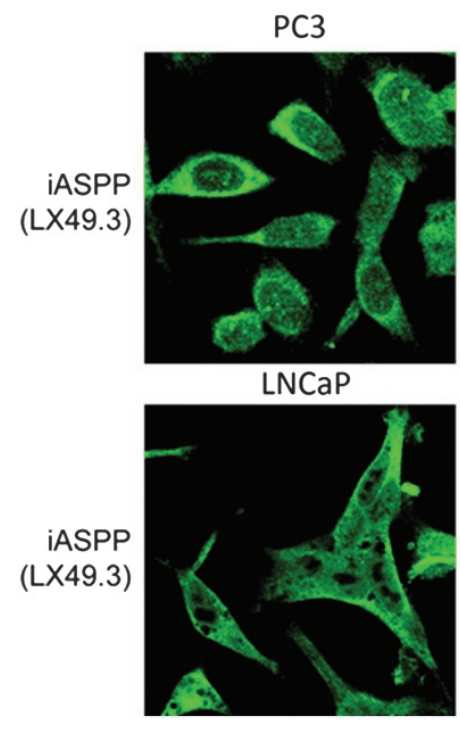

DU145

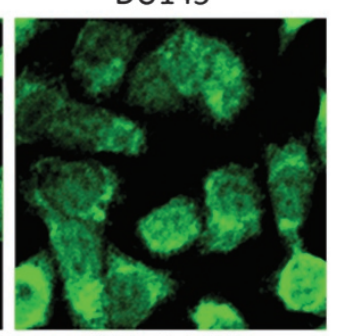

LNCaP-LN3

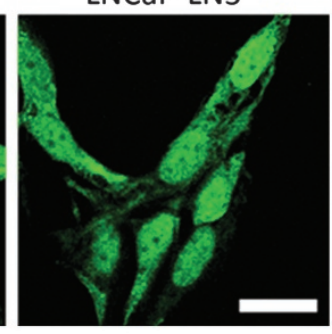

b
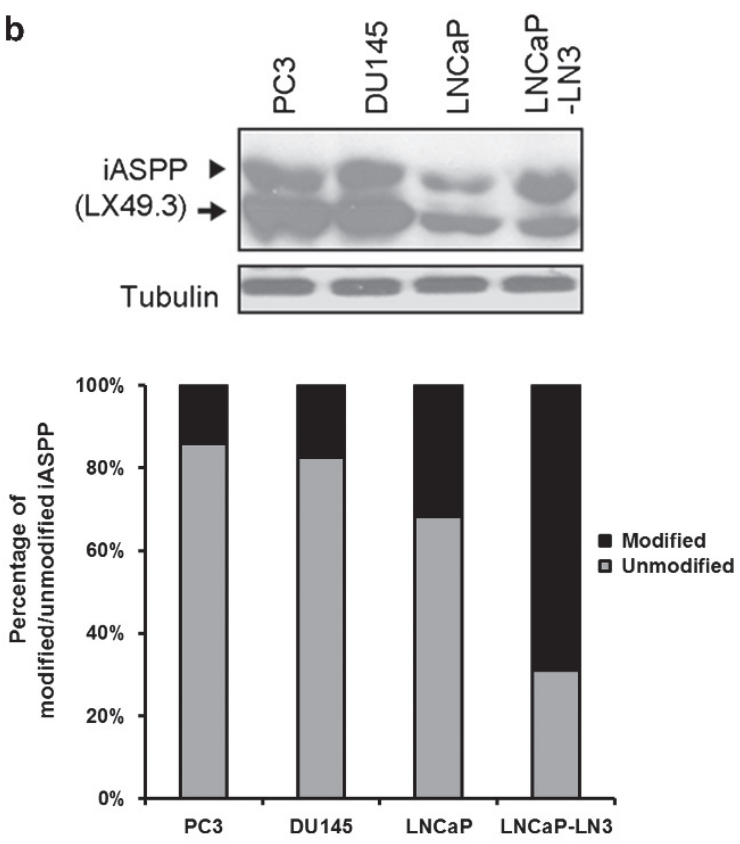

c

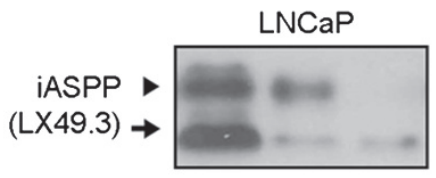

\section{LNCaP-LN3}

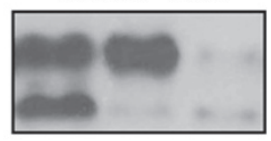

Tubulin

Lamin B
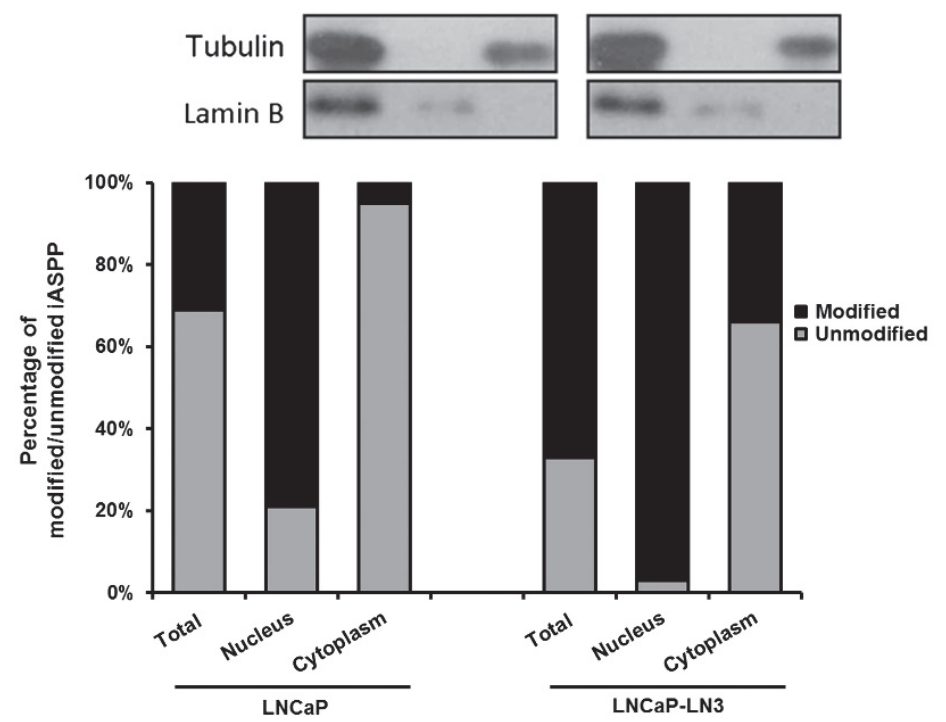

Figure 3 Phosphorylated IASPP accumulates in the nucleus of prostate cancer cells. (a) Highly metastatic LNCaP-LN3 prostate cancer cells expressed predominantly nuclear iASPP, whereas LNCaP cells with lower metastatic potential expressed iASPP with a relatively equal distribution between nucleus and cytoplasm. The p53-null PC3 cell line and p53-mutant (P233L and V274F) DU145 cell line expressed predominantly cytoplasmic iASPP. (b) iASPP migrated as two bands in an immunoblot of whole-cell protein extracts from prostate cancer cells. LNCaP-LN3 cells predominantly expressed the slower migrating iASPP band previously identified as being nuclear localised phosphorylated IASPP. LNCaP cells expressed both slow- and fast-migrating iASPP, corresponding with its roughly equal subcellular distribution. PC3 and DU145 cells, which exhibited predominantly cytoplasmic localised iASPP, expressed predominantly fast-migrating unmodified cytoplasmic iASPP. (c) The slower migrating modified iASPP band is primarily detected in nuclear protein extracts, whereas the faster migrating unmodified IASPP band is localised primarily to the cytoplasm. Invasive metastatic LNCaP-LN3 cells express a greater proportion of modified nuclear iASPP than non-invasive LNCaP cells

\section{Discussion}

The transcription factor $p 63$ is specifically expressed in prostate basal epithelial cells ${ }^{21,51-53}$ and altered p63 expression is utilised in PCa diagnosis. ${ }^{20,21,23,54,55} \mathrm{~A}$ 'Prostate-63 Cancer Diagnostic Test' has been approved by the US Food and Drug Administration (FDA) as a diagnostic marker of PCa in clinical samples. In agreement with the importance 

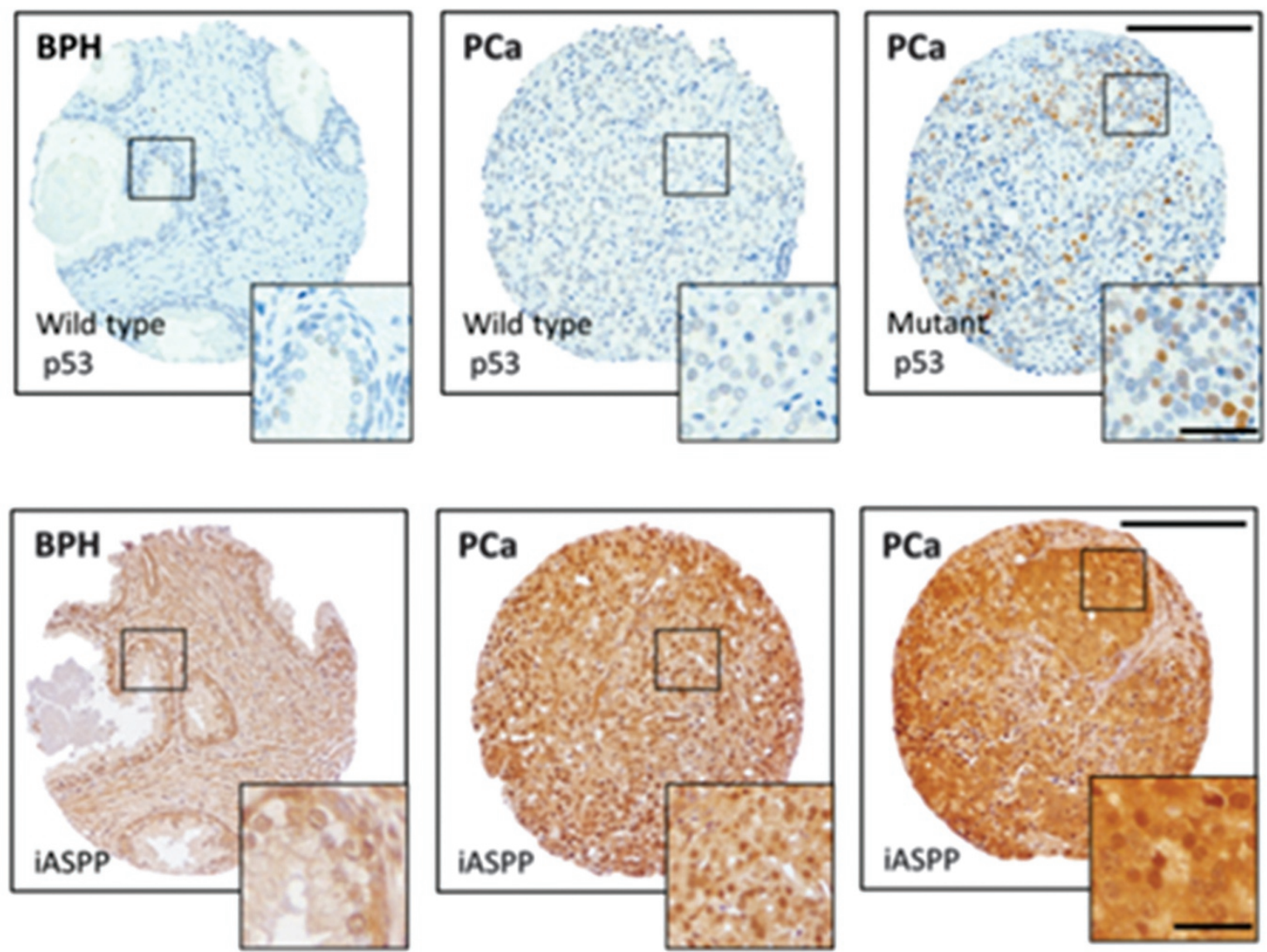

\section{Mutant}

p53
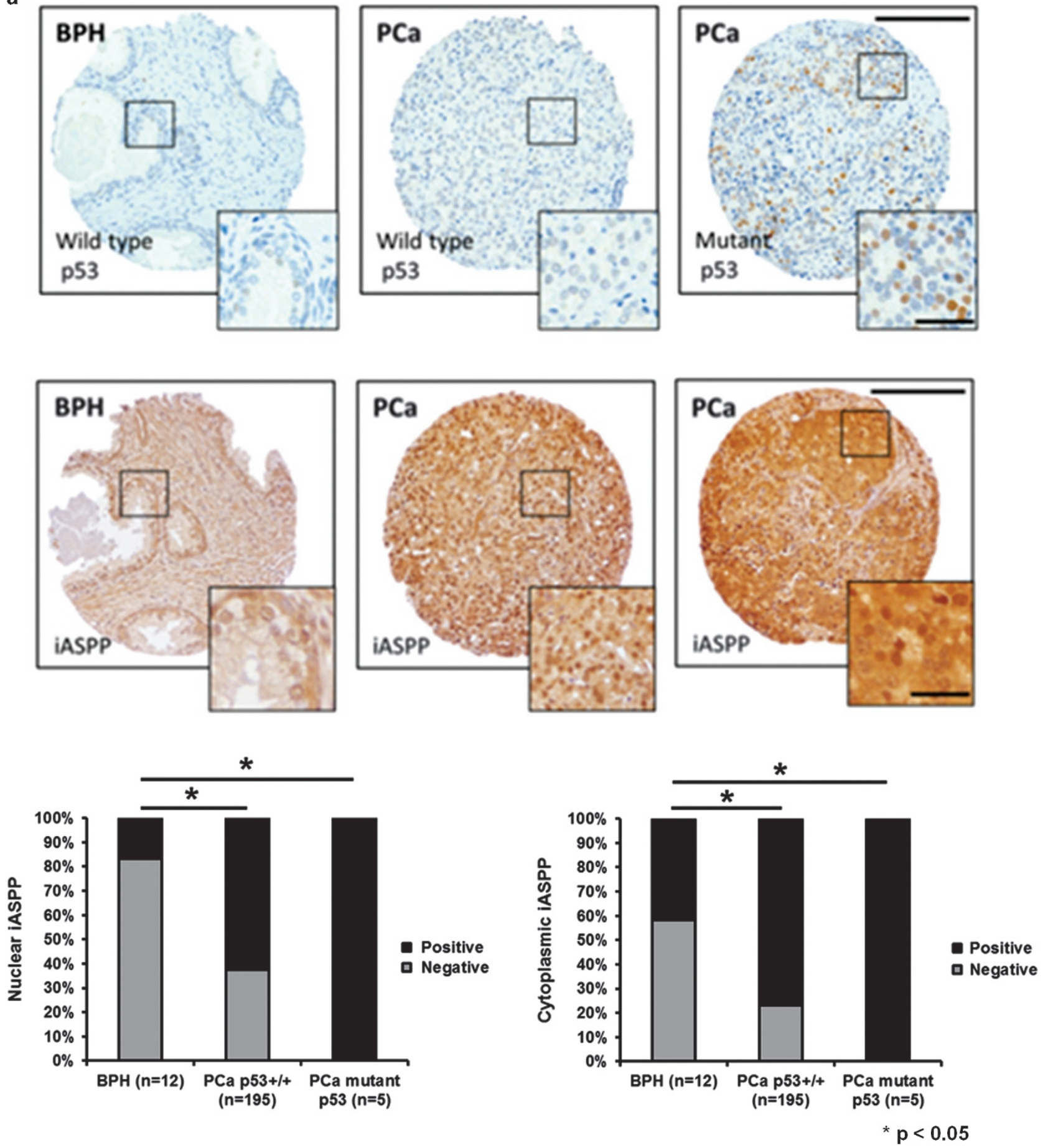

Figure 4 Nuclear iASPP expression was increased in prostate cancer samples with a high level of TP53 expression. (a) iASPP expression in human prostate cancer samples was greater in both wild-type p53 $(<30 \%$ nuclei expressing TP53) and mutant p53 ( $>30 \%$ nuclei expressing TP53) samples compared with benign prostate epithelium $(P<0.05)$. Although the number of mutant p53 prostate cancer samples was small $(n=5)$ compared with the number of wild-type p53 samples $(n=195)$ we observed that the nuclear iASPP expression was higher in mutant p53 samples compared with wild-type p53 samples. (b) TP53 and iASPP expression in cells within the leading edge of locally invading pT3a prostate cancer was compared with other areas of the sample. TP53 expression was greatest in invading prostate cancer cells within the leading edge. iASPP expression was higher in prostate cancer cells with high TP53 expression, compared with cancer cells with low TP53 expression, in capsular-invading and intra-prostatic areas of tumour. Arrow depicts direction of invasion into the prostate capsule. (c) Nuclear iASPP is co-expressed with nuclear TP53 in DU145 prostate cancer cells at the invasive margin in organotypic co-cultures. (d) Immunoprecipitation of TP53 probed with anti-iASPP and anti-TP53 antibodies demonstrated that iASPP interacts with mutant TP53 
b
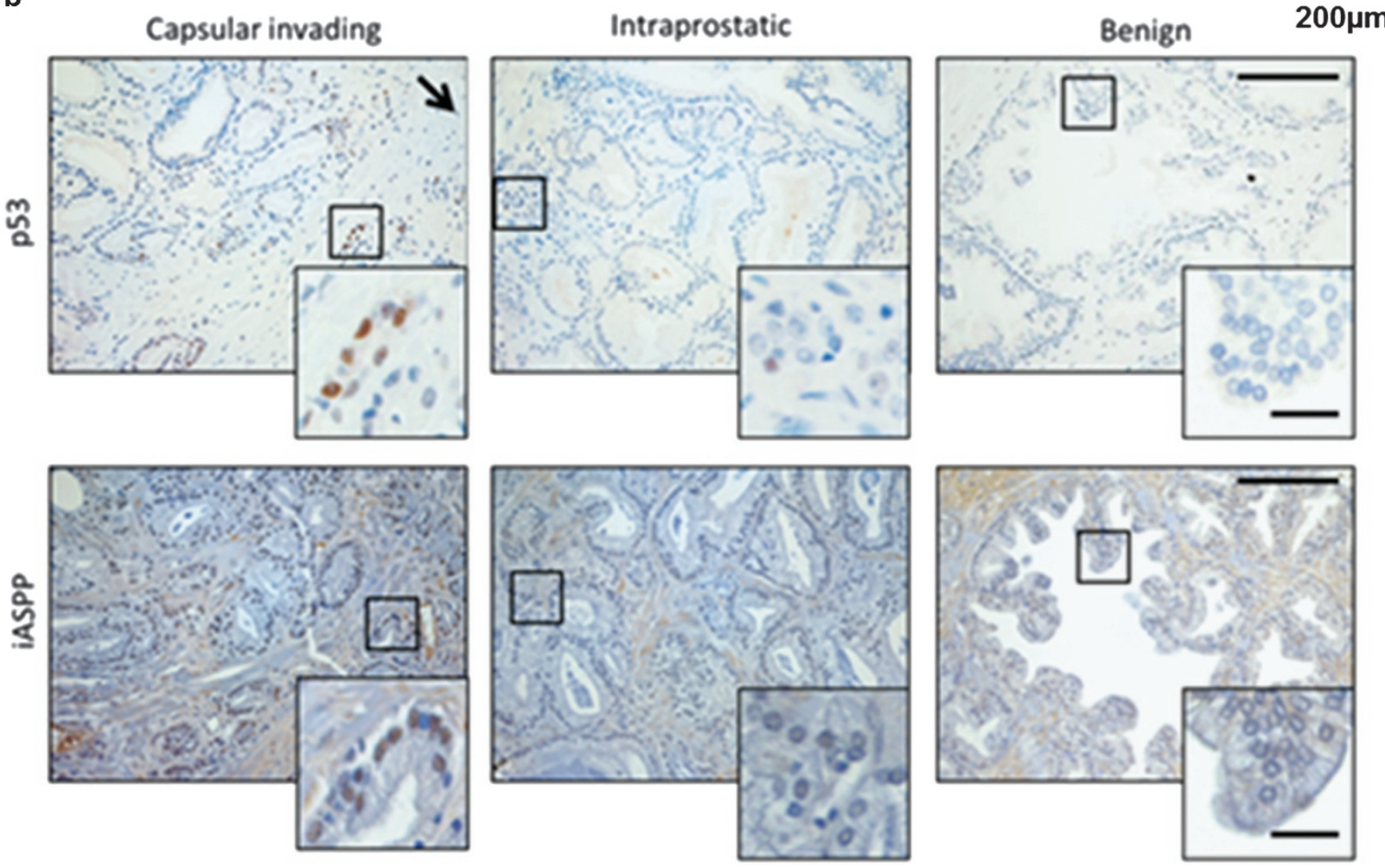

$50 \mu \mathrm{m}$
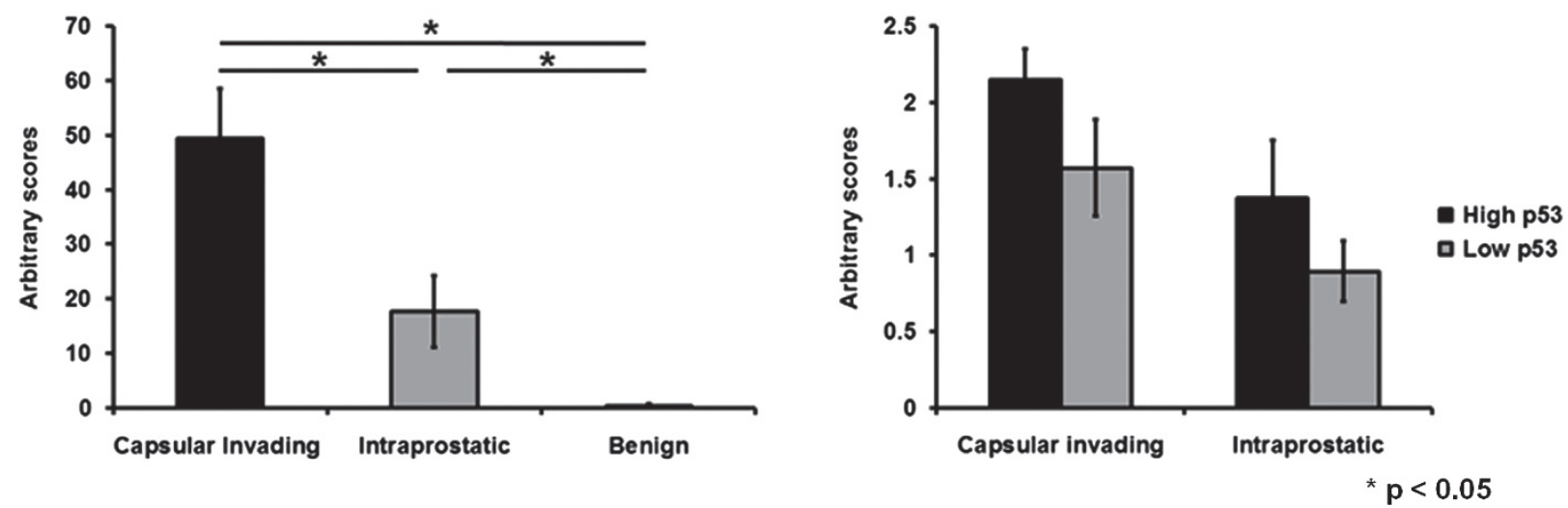

Figure 4 Continued

of p63 in the tumorigenesis of PCa, transgenic mouse studies have established a crucial role for p63 in the development of the mouse prostate gland. We show here for the first time that iASPP, a cellular regulator of p63, also plays a role in the normal development of the mouse prostate gland. We observed a detectable reduction in the number of proliferating cells in iASPP ${ }^{\Delta 8 / \Delta 8}$ mouse prostate compared with wild-type mice. Interestingly, we observed significantly fewer TP63expressing basal cells within the prostate epithelium of iASPP $^{\Delta 8 / \Delta 8}$ compared with wild-type mice, suggesting iASPP may be required to maintain the TP63-positive basal cell layer. Consistent with a role for iASPP in suppressing epithelial differentiation, we observed an increase in the expression level of Ck19, a marker of intermediate prostate epithelial cells, ${ }^{4,56}$ in iASPP $^{\Delta 8 / \Delta 8}$ mouse prostates. Cells which are phenotypically intermediate between basal and secretory cells have been found to be enriched in proliferative inflammatory atrophy lesions of the prostate, suggesting that these cells may be implicit in $\mathrm{PCa} .{ }^{57}$ Our observations in $\mathrm{IASPP}^{\Delta 8 / \Delta 8}$ mouse prostate epithelium are in complete agreement with previous findings whereby iASPP inhibits cellular senescence and binds and regulates p63 function in maintaining homeostasis of stratified epithelium in mouse skin and oesophagus. ${ }^{41,42}$ An increased differentiation process caused by iASPP deletion may accelerate the rate of commitment of p63-expressing progenitors to trans-differentiate into luminal epithelial cells via intermediate cells. In turn this could result in an enhanced diminishment of prostate progenitors. 
C

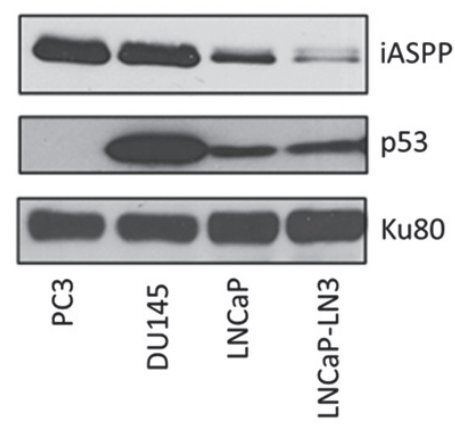

d

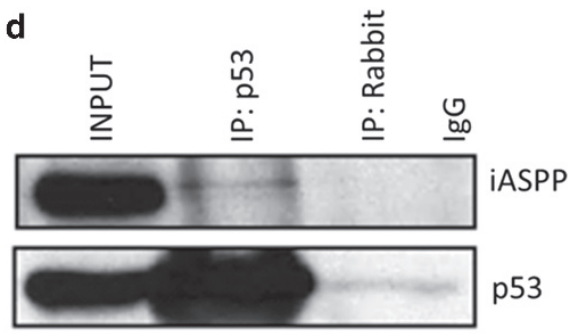

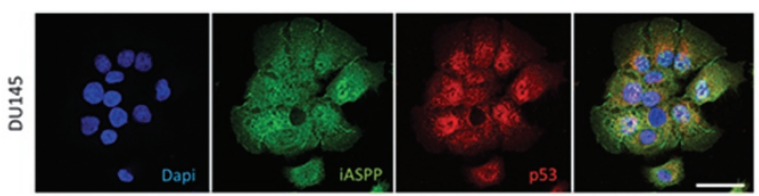

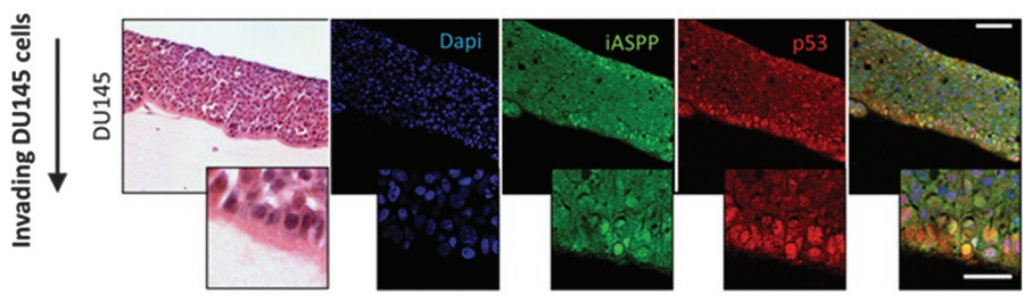

Figure 4 Continued

Table 1 Clinical characteristics of the radical retropubic prostatectomy tissue microarray cohort

\begin{tabular}{lc}
\hline & $\begin{array}{c}\text { Radical retropubic } \\
\text { prostatectomy } \\
(\boldsymbol{n = 2 0 3 )} \\
\boldsymbol{n}(\%)\end{array}$ \\
\hline Median age (range) & 63 (range $44-75)$ years \\
Preoperative PSA & \\
$\leq 10$ & $79(38.9)$ \\
$10.1-20$ & $59(29.1)$ \\
Un & $64(31.5)$ \\
Unknown & 1 \\
pT-stage & \\
$\leq$ pT2 & $94(46.3)$ \\
$\geq$ pT3 & $109(53.7)$ \\
pN-stage & \\
pN0 & \\
pN1 & $143(70.4)$ \\
pN2 & $52(25.6)$ \\
Unknown & $6(3.0)$ \\
Gleason grade & 2 \\
$\leq 6$ & \\
7 & $137(67.5)$ \\
$\geq 8$ & $36(17.7)$ \\
Unknown & $29(14.3)$ \\
Median FU (range), years & 1 \\
Developed bone metastases at & $8.8(0.1-17.7)$ \\
10 years & $43(21.2)$ \\
Prostate cancer-specific death & $37(18.2)$ \\
& \\
\hline
\end{tabular}

Abbreviations: FU, follow-up; PSA, prostate-specific antigen
We observed that loss of iASPP function results in a reduced number of p63 expressing basal cells in prostate epithelium. It has recently been shown that iASPP can regulate p63 expression via a microRNA autoregulatory feedback loop. ${ }^{42}$ It has also been demonstrated that iASPP binds p63 and directly regulates its activity. Importantly iASPP is able to inhibit cellular senescence and epithelial cell differentiation. ${ }^{41}$

It is possible that absence of iASPP induces basal prostate epithelial cells to undergo differentiation due to iASPP's ability to regulate $\mathrm{p} 63$ activity and maintain the proliferative potential of basal epithelial cells. Future studies are needed to understand how iASPP deficiency causes a reduction in p63 expressing prostate epithelial basal cells. Regardless of this our observation that nuclear iASPP expression was increased in $\mathrm{PCa}$ progression was interesting given that the expression of TP63 is frequently lost in PCa. ${ }^{24}$ It is known that p63 expression defines the basal epithelial cell lineage, and we speculate that when PCa cells enter their metastatic phase there is possible cellular reprogramming, lineage change and an epithelial-to-mesenchymal transition (EMT). p63 is known to regulate key epithelial proteins such as cadherins and cell adhesion molecules. ${ }^{58}$ Moreover, p53 is an important inhibitor of $\mathrm{EMT}^{59}$ and most PCa express wild-type p53. ${ }^{2-6}$ Therefore an inhibitor of p53 such as iASPP could play an important role in facilitating prostate epithelial cells to undergo EMT. We showed recently that nuclear iASPP has the highest p53 binding and p53 inhibition potency. ${ }^{25}$ It is perhaps via this mechanism that nuclear iASPP contributes to loss of p53 function, induction of EMT, loss of the epithelial cell lineage 

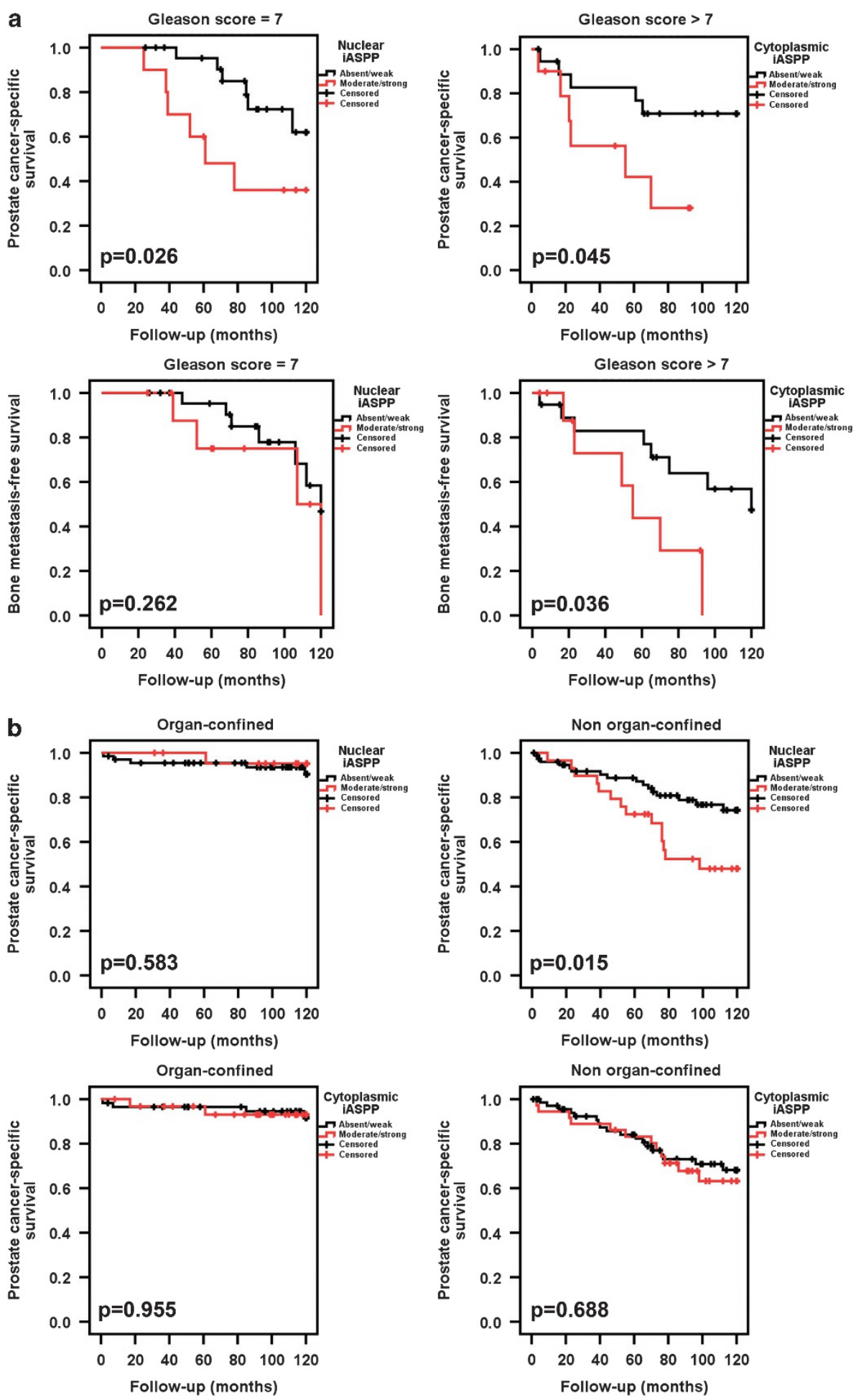

Figure 5 Increased iASPP expression in prostate cancer samples is associated with an adverse clinical prognosis. (a) Increased nuclear iASPP expression in intermediate grade (Gleason sum score 7) prostate cancers was associated with increased prostate cancer-specific death after 10 years of follow-up following radical surgery. Increased cytoplasmic iASPP in high grade (Gleason sum score $\geq 8$ ) prostate cancer samples was associated with an increased risk of both prostate cancer bone metastasis development and prostate cancer-specific death after 10 years of follow-up following radical surgery. (b) Increased nuclear iASPP expression was associated with a poor clinical outcome in men treated surgically for non organ-confined ( $\geq$ PT3a) prostate cancer. High nuclear iASPP in this group of patients was associated with an increased risk of prostate cancerspecific death following radical surgery 
Table 2 Multivariate analysis of clinical prognostic factors for the development of prostate cancer bone metastasis and prostate cancer-specific death in the radical retropubic prostatectomy tissue microarray cohort

\begin{tabular}{|c|c|c|c|c|}
\hline & \multicolumn{2}{|c|}{ Bone metastases } & \multicolumn{2}{|c|}{ Prostate cancer death } \\
\hline & HR (95\% Cl) & $\boldsymbol{P}$ & HR (95\% Cl) & $\boldsymbol{P}$ \\
\hline \multicolumn{5}{|l|}{ All prostate cancer cases } \\
\hline pT stage & $1.92(0.96-3.85)$ & 0.065 & $4.33(1.75-10.69)$ & 0.001 \\
\hline pN stage & $1.58(0.88-2.86)$ & 0.129 & $1.96(1.05-3.67)$ & 0.035 \\
\hline PSA & $1.01(0.99-1.02)$ & 0.505 & $1.00(0.99-1.02)$ & 0.828 \\
\hline Gleason group & $2.32(1.55-3.47)$ & $<0.001$ & $1.95(1.23-3.10)$ & 0.004 \\
\hline Nuclear iASSPP expression & $0.97(0.47-1.98)$ & 0.925 & $1.82(0.91-3.66)$ & 0.092 \\
\hline Cytoplasmic iASPP expression & $0.98(0.49-1.94)$ & 0.948 & $1.26(0.63-2.53)$ & 0.508 \\
\hline \multicolumn{5}{|l|}{ Gleason 7 prostate cancer cases } \\
\hline pT stage & $6.36(0.91-44.28)$ & 0.062 & $3.72(0.74-18.63)$ & 0.110 \\
\hline pN stage & $1.18(0.31-4.54)$ & 0.813 & $1.13(0.36-3.60)$ & 0.833 \\
\hline PSA & $1.04(1.0-1.09)$ & 0.055 & $0.99(0.94-1.04)$ & 0.576 \\
\hline Nuclear iASPP expression & $3.81(0.80-18.1)$ & 0.093 & $3.72(1.10-12.61)$ & 0.035 \\
\hline Cytoplasmic iASPP expression & $0.56(0.11-3.0)$ & 0.501 & $0.53(0.12-2.36)$ & 0.403 \\
\hline \multicolumn{5}{|l|}{ Gleason $\geq 8$ prostate cancer cases } \\
\hline pT stage & $3.84(0.91-16.18)$ & 0.066 & $8.20(0.91-73.57)$ & 0.06 \\
\hline pN stage & $0.70(0.19-2.53)$ & 0.585 & $1.84(0.46-7.33)$ & 0.389 \\
\hline PSA & $1.01(0.99-1.03)$ & 0.56 & $1.00(0.98-1.02)$ & 0.766 \\
\hline Nuclear iASPP expression & $0.70(0.16-3.13)$ & 0.639 & $0.22(0.03-1.47)$ & 0.119 \\
\hline Cytoplasmic iASPP expression & $4.58(1.24-16.98)$ & 0.023 & $8.17(1.46-45.73)$ & 0.017 \\
\hline
\end{tabular}

Abbreviations: $\mathrm{Cl}$, confidence interval; HR, hazard ratio; iASPP, inhibitor of apoptosis-stimulating protein of p53; PSA, prostate-specific antigen

and concomitant loss of p63 expression. This hypothesis warrants further investigation.

The observation that iASPP is predominantly expressed in the nucleus, and to a lesser degree in the cytoplasm of basal prostate epithelial cells in benign prostate samples, suggests that iASPP may maintain the proliferative potential of basal epithelial cells. The finding that iASPP co-localises with TP63 within the nucleus of benign prostate epithelial cells agrees with previous findings where iASPP binds and directly regulates TP63 function. ${ }^{41}$ We observed that iASPP expression was increased in the nucleus and cytoplasm of $\mathrm{PCa}$ cells in a cohort of over 200 PCa samples compared with benign prostate epithelial samples. This agrees with an oncogenic role for iASPP in PCa development. It is also in agreement with numerous findings showing an increase in iASPP expression in human cervical, head and neck, ovarian, melanoma and a small cohort of PCa samples. ${ }^{25,39,40,60,61}$ To date, however, changes in iASPP expression have not been associated with long-term prognosis in PCa. Our detailed analysis of iASPP expression patterns in a cohort of $61 \mathrm{PCa}$ samples containing benign prostate epithelial cells adjacent to areas of cancer allowed us for the first time to obtain evidence of a potential 'field change effect' of iASPP expression. iASPP expression levels in the histologically normal prostate directly adjacent to cancer were seen to be significantly greater than benign epithelium in men without $\mathrm{PCa}$. This observation is in keeping with other published reports, suggesting that a 'field change' phenomenon or 'field cancerisation' effect exists during malignant transformation of prostate epithelium. ${ }^{62-70}$ Furthermore we observed that nuclear iASPP is enriched within PCa cells at the invasive front of locally invading tumours in vivo, and within the experimentally derived metastatic PCa cell line LNCaP-LN3 compared with parental $\mathrm{LNCaP}$ cells in vitro. Interestingly, LNCaP cells contain wild-type p53 and the majority of human PCa also express wild-type p53 with this gene only mutated or deleted in $~ 30 \%$ of the cases. Our findings concur with those in a recent study showing a nuclear enrichment of iASPP in malignant metastatic human melanoma cells, ${ }^{25}$ and this is interesting given that both melanoma and PCa generally have a lower rate of p53 mutation than many other cancer types.

We observed that cytoplasmic iASPP expression, in addition to nuclear iASPP, is detected in PCa samples, and increased cytoplasmic iASPP was associated with an increased risk of both metastasis formation and PCa-specific death following radical surgery. We do not currently understand the biological importance of cytoplasmic iASPP, however p53 has previously been detected in the cytoplasm as well as the nucleus of cells, and levels of cytoplasmic iASPP expression have been associated with an adverse prognosis in other cancer types. ${ }^{39}$ It is possible that cytoplasmic iASPP may inhibit the activity of cytoplasmic $p 53$, although it is known that nuclear iASPP has a higher binding affinity to p53. ${ }^{25}$ Cytoplasmic iASPP may influence aspects of p53 function independent of its transcriptional activity, however further studies will be necessary to fully elucidate the biological role of cytoplasmic iASPP.

These findings suggest that changes in iASPP expression and subcellular localisation may potentially be useful clinically as a biomarker predictive of clinically aggressive PCa. The results of this study identify iASPP as being a key molecular switch in the progression of PCa to an invasive and metastatic phenotype with a lethal outcome.

\section{Materials and Methods}

Mice. The generation of iASPP ${ }^{\Delta 8 / \Delta 8}$ mice has been described previously. ${ }^{41}$ All animal procedures were approved by local ethical review and licensed by the UK Home Office. All iASPP ${ }^{\Delta 8 / \Delta 8}$ mice analysed in this study were paired with age-matched wild-type controls and these were littermates wherever possible. Prostate tissues were fixed in $10 \%$ buffered formalin overnight, dehydrated in an 
ethanol series and cleared in xylene before being embedded in paraffin. The entire prostate was embedded as a whole in a consistent manner to avoid problems with changes in orientation of the lobes. Four micrometre sections were cut for thickness for experimental analysis. For cell proliferation studies, mice were injected with $30 \mu \mathrm{g} \mathrm{BrdU}$ per gram of body weight $24 \mathrm{~h}$ before being killed.

Cell lines. LNCaP (May 2003), PC-3 (February 2004), and DU145 (December 2011) cells were purchased from ATCC (Manassas, VA, USA). LNCaP-LN3 cells were a generous gitt from Professor Curtis Pettaway (Department of Urology, The University of Texas MD Anderson Cancer Center, Houston, TX, USA). These cells were maintained in RPMI 1640 medium supplemented with 10\% fetal calf serum (FCS) (GE Healthcare Life Sciences, Little Chalfont, UK), sodium pyruvate, MEM vitamins and MEM non-essential amino acids (Invitrogen, Paisley, UK) and were used for no longer than 6 months post resuscitation. Normal human fibroblast (NHF) cells were maintained in Dulbecco's Modified Eagle Medium (DMEM) (Invitrogen) supplemented with $10 \%$ FCS. All cell lines were supplemented with $100 \mathrm{U} / \mathrm{ml}$ of penicillin and streptomycin (Invitrogen) and incubated at $37^{\circ} \mathrm{C}$ in a $5 \% \mathrm{CO}_{2}$ atmosphere.

Organotypic culture. A suspension of $5 \times 10^{5} \mathrm{NHFs}$ was prepared in DMEM for each organotypic culture. One millilitre scaffold gel plugs were prepared for each organotypic culture containing $5 \times 10^{5} \mathrm{NHFs}, 10 \% \mathrm{FCS}$ and $1: 1$ rat tail collagen type I/Matrigel (Becton Dickinson, Oxford, UK) in DMEM, and after overnight incubation at $37^{\circ} \mathrm{C}, 5 \times 10^{5} \mathrm{PCa}$ cells (PC3, DU145, LNCaP and LNCaP-LN3) were plated onto the upper surface of each gel plug and incubated for a further $24 \mathrm{~h}$. A sterile nylon square in a Petri dish was covered with $250 \mu \mathrm{l}$ gel containing $10 \% \mathrm{FCS}$, $70 \%$ collagen and DMEM and polymerised by incubating at $37^{\circ} \mathrm{C}$ for $20 \mathrm{~min}$. Ten millilitre $1 \%$ glutaraldehyde (Sigma, Gillingham, UK) in phosphate buffered saline (PBS) was then added to the Petri dish and the nylon sheets incubated at $4^{\circ} \mathrm{C}$ for $1 \mathrm{~h}$ then washed in PBS followed by DMEM and then incubated at $4{ }^{\circ} \mathrm{C}$ overnight. The nylon sheets were then mounted on metal scaffolds and placed in a Petri dish, and the NHF/PCa cell-containing gel plugs were placed onto the nylon sheet and incubated at $37^{\circ} \mathrm{C}$ for 10 days with culture media just beneath the nylon sheet. Gels were then formalin-fixed, processed and sectioned for histology.

Protein extracts. Protein extracts were obtained from cultured cells or homogenised mouse prostate using urea buffer. Mouse prostate lysates were sonicated prior to protein quantification. Protein concentrations were determined using a protein assay reagent system (Bio-Rad, Hercules, CA, USA) and spectrophotometric analysis at $595 \mathrm{~nm}$. The absorbance of samples was compared with a standard curve derived from known concentrations of bovine serum albumin (BSA; Sigma).

Antibodies. Primary antibodies used in this study for Western blotting (WB), immunofluorescence $(\mathrm{IF})$, and immunohistochemistry $(\mathrm{IHC})$ include: rat anti-BrdU (ab6326, IF 1:200); rabbit anti-Ck 19 (ab53119, WB 1:500); rabbit anti-Ck 5 (ab53121, WB 1:750, IF 1:3000); rabbit anti-Ck 8 (ab59400, WB 1:500, IF $1: 200)$; mouse anti-lamin B (ab8983, WB 1: 1000); rabbit anti-tubulin (ab52901, WB $1: 2000$ ) (Abcam, Cambridge, UK); mouse anti-iASPP (purified LX049.3, IF 1:250, IHC 1:250, WB 1:1000); rabbit anti-ki67 (Vector Laboratories, Peterborough, UK; IHC 1:200); mouse anti-Ku80 (ThermoFisher Scientific, Loughborough, UK; WB 1:2000); rabbit anti-p53 (CM1, WB 1:1000, IF 1:250); mouse anti-p53 (DO-1, WB 1: 1000); mouse anti-p63 (4A4, Santa Cruz, Dallas, TX, USA; WB 1: 1000; IF/HC 1:200).

Secondary antibodies (Invitrogen unless stated) used in this study include: rabbit anti-mouse horseradish peroxidase (HRP) (Dako, Ely, UK; WB $1: 2000)$, swine antirabbit (Dako, WB 1: 2000), goat alexa-fluor 488 anti-rabbit (IF $1: 400)$, goat alexafluor 488 anti-mouse (IF 1:400); donkey alexa-fluor 488 anti-mouse (IF 1:400); donkey alexa-fluor 647 anti-mouse (IF $1: 400$ ), donkey alexa-fluor 488 anti-rabbit (IF 1:400), donkey alexa-fluor 647 anti-rabbit (IF 1:400); goat biotinylated antimouse IgG (Vector Laboratories, IHC 1 : 250); goat biotinylated anti-rabbit lgG (Vector Laboratories, IHC 1:250).

Immunoblotting. For whole-cell extracts, cells were lysed in urea buffer containing $8 \mathrm{M}$ urea, $1 \mathrm{M}$ thiourea, $0.5 \%$ 3-[(3-cholamidopropyl)dimethylammonio]-2hydroxy-1-propanesulfonate, $50 \mathrm{mM}$ dithiothreitol and $24 \mathrm{mM}$ spermine. Nuclear and cytoplasmic extract fractions were prepared from $5 \times 10^{5}$ cells using a nuclei isolation kit (NUC101-1KT, Sigma-Aldrich, UK) according to the manufacturer's instructions and the fractions were then directly dissolved in urea buffer. After centrifugation the supernatant was dissolved in SDS loading buffer prior to immunoblot analysis. A total of $100 \mu \mathrm{g}$ of protein extract was loaded per lane into
SDS-polyacrylamide gels. Gels were transferred onto nitrocellulose membrane (Protran, Sigma-Aldrich) and the resulting blots incubated first with primary antibody for $16 \mathrm{~h}$ at $4{ }^{\circ} \mathrm{C}$, and then with the appropriate HRP-conjugated secondary antibody (Dako). Protein expression was visualised by enhanced chemiluminescent detection (Amersham Biosciences, Little Chalfont, UK) using X-ray film. All autoradiographs were scanned using a photo scanner. For the detection of specific iASPP isoforms extracts were immunoblotted on a $16 \times 12 \mathrm{~cm} 6 \%$ gel. The antibody used for iASPP immunoblotting was LX49.3 $3^{41}$ unless otherwise stated.

Immunocytochemistry. Cells grown to $70-80 \%$ confluence on coverslips were fixed with $4 \%$ paraformaldehyde solution, permeabilised with $0.1 \%$ Triton $X$ solution, blocked with $0.2 \%$ BSA and primary antibody was added for $1 \mathrm{~h}$ at room temperature. Secondary antibody and 4',6-diamidino-2-phenylindole (DAPI) was then added and coverslips were mounted with mowiol-glycerol solution.

Immunoprecipitation. Cells grown on $15 \mathrm{~cm}$ dishes were washed with cold PBS and lysed with $100 \mathrm{mM} \mathrm{NaCl}, 1 \mathrm{mM}$ ethylenediaminetetraacetic acid (EDTA), $20 \mathrm{mM}$ Tris (NET) 1\% NP-40 IP buffer containing protease inhibitors. Cell lysates were centrifuged at 13200 r.p.m., $4^{\circ} \mathrm{C}$, for $20 \mathrm{~min}$, and the protein concentration of the supernatant determined. Fifty microlitres of each lysate was used as an input control. Protein $\mathrm{G}$ sepharose beads were washed in cold PBS, made up to a ratio of $1: 1$ with PBS and stored at $4^{\circ} \mathrm{C}$. Each lysate was pre-cleared using $30 \mu$ l of slurry beads and rotation for $60 \mathrm{~min}$ at $4{ }^{\circ} \mathrm{C}$, and then lysates were centrifuged at $4{ }^{\circ} \mathrm{C}$. Ten microlitres of antibody was added to the supernatant along with $30 \mu \mathrm{l}$ of fresh protein $\mathrm{G}$ sepharose beads and the sample rotated overnight at $4^{\circ} \mathrm{C}$. Beads were washed in NET IP buffer and $0.2 \%$ NP-40 before being centrifuged further. The supernatant was then removed and sample buffer added to the beads. Samples were then boiled, centrifuged and sample buffer added.

Human tissue samples. TMA sections were obtained from the Department of Urology, University of Bern, Switzerland. Following IHC protein expression, scores for each core were assigned by a histopathologist (FF and VS). Pathologic tumour stage 3 (pT3) PCa whole-mount sections were obtained from the Oxford Centre for Histopathology Research, Nuffield Division of Clinical Laboratory Sciences, University of Oxford, Oxford Radcliffe Hospitals National Health Service (NHS) Trust, Oxford, UK. After IHC protein expression scores for different areas of interest were assigned by a histopathologist (CV). This study had ethics committee approval (reference number 09/H0606/78).

IHC and IF. Sections were de-paraffinised in histoclear and rehydrated through graded alcohols to water. Endogenous peroxidise activity was inactivated where appropriate using $3 \% \mathrm{H}_{2} \mathrm{O}_{2}$ in methanol, and where necessary antigen retrieval was performed using boiling citric acid (human tissue, TP63) or EDTA (mouse tissue, TP63 and iASPP) buffers. Sections were blocked with $5 \%$ normal goat serum and incubated with primary antibody at $4{ }^{\circ} \mathrm{C}$ overnight. For IHC, a biotinylated secondary antibody was added for $30 \mathrm{~min}$ followed by an avidin/biotin-based peroxidase solution and incubated with 3,3'-diaminobenzidine solution before counterstaining with haematoxylin. For IF, an appropriate secondary antibody with DAPI was added for $1 \mathrm{~h}$. All sections were dehydrated using increasing percentages of ethanol followed by histoclear and mounted in mowiol-glycerol medium. The sections were viewed and photographed with a confocal $(\mathrm{IF})$ or light $(\mathrm{IHC})$ microscope. Where described H\&E and Alcian blue staining, were performed using standard techniques.

Tissue apoptosis assay. Apoptotic cells were detected using an ApopTag Red In Situ Apoptosis Detection Kit (Merck Millipore, Watford, UK) according to the manufacturer's recommended protocol.

Quantification of prostate lobe size and protein expression in mouse and human prostate tissue studies. The size of the prostate ventral and dorsolateral lobes was measured based on the assumption that that they are elliptical in shape. Four microlitre sections were cut through the entire prostate and every tenth section stained using H\&E. The largest surface area of each lobe section was calculated using Image J software (NIH Image, Bethesda, MD, USA), and the volume of each lobe calculated using the depth of each lobe (taken from the number of sections available) using the equation: lobe volume $=(4 / 3) \times \pi \times r^{1} \times r^{2} \times r^{3}$ (where $r^{1}=$ height, $r^{2}=$ width, $r^{3}=$ depth).

All cell counts in mouse prostate tissue studies were performed using a minimum of 1000 cells. Four fields of view at $\times 20$ magnification per slide were randomly 
selected for each prostate lobe. Three different slides were used per analysis and per animal. Analysis was performed using Image $\mathrm{J}$ software (NIH Image).

iASPP expression intensity in human tissue samples was scored by a histopathologist (CV, FF, VS). The maximum iASPP expression within each TMA core was recorded. Nuclear expression was graded as absent (0), weak (1), moderate (2) or strong (3). Cytoplasmic expression was graded as absent (0), weak (1) or strong (2). iASPP expression in cells invading the prostatic capsule, or within intra-prostatic tumour, along with benign prostate epithelium in pT3 PCa whole-mount sections was scored in a similar manner by a histopathologist (CV).

Statistical methods and patient survival analysis. Patient survival analysis was performed by Kaplan-Meier analysis using a log rank test and SPSS statistics 20 software (IBM, Portsmouth, UK). Paired and unpaired t-tests, and Mann-Whitney U-tests, were performed using GraphPad Prism (GraphPad, La Jolla, CA, USA) or excel software. All statistical tests were performed as two-tailed tests. Differences were considered significant at a $P$-value $<0.05$. All error bars shown on figures are S.E.M.

\section{Conflict of Interest}

The authors declare no conflict of interest.

Acknowledgements. We thank Mark Shipman for his technical assistance. We are grateful to Professor Hans Lilia for his critical review of the manuscript. This work was funded by the Ludwig Institute for Cancer Research, Medical Research Council (EVM), the National Institute for Health Research (RJB) and the Academy of Medical Sciences (RJB). CVs research time was funded by the National Institute for Health Research (NIHR) Oxford Biomedical Research Centre based at the Oxford University Hospitals NHS Trust and the University of Oxford. FCH acknowledges funding from the NIHR through the Oxford Biomedical Research Centre and its surgical theme.

1. Levine AJ, Oren M. The first 30 years of $p 53$ : growing ever more complex. Nat Rev Cance 2009; 9: 749-758

2. Taylor BS, Schultz N, Hieronymus H, Gopalan A, Xiao Y, Carver BS et al. Integrative genomic profiling of human prostate cancer. Cancer Cell 2010; 18: 11-22.

3. Schlomm T, Iwers L, Kirstein P, Jessen B, Kollermann J, Minner S et al. Clinical significance of p53 alterations in surgically treated prostate cancers. Mod Pathol 2008; 21: 1371-1378.

4. Henke RP, Kruger $E$, Ayhan $N$, Hubner D, Hammerer $P$, Huland $H$. Immunohistochemical detection of p53 protein in human prostatic cancer. J Urol 1994; 152: 1297-1301.

5. Prendergast NJ, Atkins MR, Schatte EC, Paulson DF, Walther PJ. p53 immunohistochemical and genetic alterations are associated at high incidence with post-irradiated locally persistent prostate carcinoma. J Urol 1996; 155: 1685-1692.

6. Voeller HJ, Sugars LY, Pretlow T, Gelmann EP. p53 oncogene mutations in human prostate cancer specimens. J Urol 1994; 151: 492-495.

7. Bostwick DG, Pacelli A, Lopez-Beltran A. Molecular biology of prostatic intraepithelial neoplasia. Prostate 1996; 29: 117-134.

8. Rinker-Schaeffer CW, Partin AW, Isaacs WB, Coffey DS, Isaacs JT. Molecular and cellular changes associated with the acquisition of metastatic ability by prostatic cancer cells. Prostate 1994; 25: 249-265.

9. Aprikian AG, Sarkis AS, Fair WR, Zhang ZF, Fuks Z, Cordon-Cardo C. Immunohistochemical determination of p53 protein nuclear accumulation in prostatic adenocarcinoma. J Urol 1994; 151: 1276-1280.

10. Bookstein R, MacGrogan D, Hilsenbeck SG, Sharkey F, Allred DC. p53 is mutated in subset of advanced-stage prostate cancers. Cancer Res 1993; 53: 3369-3373.

11. Eastham JA, Stapleton AM, Gousse AE, Timme TL, Yang G, Slawin KM et al. Association of p53 mutations with metastatic prostate cancer. Clin Cancer Res 1995; 1: 1111-1118.

12. Effert PJ, McCoy RH, Walther PJ, Liu ET. p53 gene alterations in human prostate carcinoma. J Urol 1993; 150: 257-261.

13. Heidenberg HB, Sesterhenn IA, Gaddipati JP, Weghorst CM, Buzard GS, Moul JW et al. Alteration of the tumor suppressor gene p53 in a high fraction of hormone refractory prostate cancer. J Urol 1995; 154(2 Pt 1): 414-421.

14. Navone NM, Troncoso P, Pisters LL, Goodrow TL, Palmer JL, Nichols WW et al. p53 protein accumulation and gene mutation in the progression of human prostate carcinoma J Natl Cancer Inst 1993; 85: 1657-1669.

15. Kubota $Y$, Shuin $T$, Uemura H, Fujinami $K$, Miyamoto $H$, Torigoe $S$ et al. Tumor suppressor gene p53 mutations in human prostate cancer. Prostate 1995; 27: 18-24.

16. Muller PA, Trinidad AG, Timpson P, Morton JP, Zanivan S, van den Berghe PV et al. Mutan p53 enhances MET trafficking and signalling to drive cell scattering and invasion. Oncogene 2013; 32: 1252-1265

17. Muller PA, Caswell PT, Doyle B, Iwanicki MP, Tan EH, Karim S et al. Mutant p53 drives invasion by promoting integrin recycling. Cell 2009; 139: 1327-1341.
18. Adorno M, Cordenonsi M, Montagner M, Dupont S, Wong C, Hann B et al. A Mutant-p53/ Smad complex opposes p63 to empower TGFbeta-induced metastasis. Cell 2009; 137: 87-98.

19. Flores ER, Sengupta S, Miller JB, Newman JJ, Bronson R, Crowley D et al. Tumor predisposition in mice mutant for p63 and p73: evidence for broader tumor suppressor functions for the p53 family. Cancer Cell 2005; 7: 363-373.

20. Davis LD, Zhang W, Merseburger A, Young D, Xu L, Rhim JS et al. p63 expression profile in normal and malignant prostate epithelial cells. Anticancer Res 2002; 22: 3819-3825.

21. Signoretti S, Waltregny D, Dilks J, Isaac B, Lin D, Garraway L et al. p63 is a prostate basal cell marker and is required for prostate development. Am J Pathol 2000; 157: 1769-1775.

22. Pignon JC, Grisanzio C, Geng Y, Song J, Shivdasani RA, Signoretti S. p63-expressing cells are the stem cells of developing prostate, bladder, and colorectal epithelia. Proc Natl Acad Sci USA 2013; 110: 8105-8110.

23. Shah RB, Zhou M, LeBlanc M, Snyder M, Rubin MA. Comparison of the basal cell-specific markers, 34betaE12 and p63, in the diagnosis of prostate cancer. Am J Surg Pathol 2002; 26: $1161-1168$

24. Parsons JK, Gage WR, Nelson WG, De Marzo AM. p63 protein expression is rare in prostate adenocarcinoma: implications for cancer diagnosis and carcinogenesis. Urology 2001; 58 : 619-624.

25. Lu M, Breyssens $\mathrm{H}$, Salter V, Zhong S, Hu Y, Baer $\mathrm{C}$ et al. Restoring $\mathrm{p} 53$ function in human melanoma cells by inhibiting MDM2 and cyclin B1/CDK1-phosphorylated nuclear iASPP. Cancer Cell 2013; 23: 618-633.

26. Sullivan A, Lu X. ASPP: a new family of oncogenes and tumour suppressor genes. Br J Cancer 2007; 96: 196-200.

27. Trigiante G, Lu X. ASPP [corrected] and cancer. Nat Rev Cancer 2006; 6: 217-226.

28. Vives V, Su J, Zhong S, Ratnayaka I, Slee E, Goldin R et al. ASPP2 is a haploinsufficient tumor suppressor that cooperates with p53 to suppress tumor growth. Genes Dev 2006; 20 : 1262-1267.

29. Kampa KM, Acoba JD, Chen D, Gay J, Lee H, Beemer K et al. Apoptosis-stimulating protein of p53 (ASPP2) heterozygous mice are tumor-prone and have attenuated cellular damageresponse thresholds. Proc Natl Acad Sci USA 2009; 106: 4390-4395.

30. Tordella L, Koch S, Salter V, Pagotto A, Doondeea JB, Feller SM et al. ASPP2 suppresses squamous cell carcinoma via RelA/p65-mediated repression of p63. Proc Natl Acad Sci USA 2013; 110: 17969-17974

31. Wang Y, Wang XD, Lapi E, Sullivan A, Jia W, He YW et al. Autophagic activity dictates the cellular response to oncogenic RAS. Proc Natl Acad Sci USA 2012; 109: 13325-13330.

32. Wang Y, Godin-Heymann N, Dan Wang X, Bergamaschi D, Llanos S, X Lu. ASPP1 and ASPP2 bind active RAS, potentiate RAS signalling and enhance p53 activity in cancer cells. Cell Death Differ 2013; 20: 525-534.

33. Wang XD, Lapi E, Sullivan A, Ratnayaka I, Goldin R, Hay R et al. SUMO-modified nuclear cyclin D1 bypasses Ras-induced senescence. Cell Death Differ 2011; 18: 304-314.

34. Sottocornola R, Royer C, Vives V, Tordella L, Zhong S, Wang Y et al. ASPP2 binds Par-3 and controls the polarity and proliferation of neural progenitors during CNS development. Dev Cell 2010; 19: 126-137.

35. Cong W, Hirose T, Harita Y, Yamashita A, Mizuno K, Hirano H et al. ASPP2 regulates epithelial cell polarity through the PAR complex. Curr Biol 2010; 20: 1408-1414.

36. Bergamaschi D, Samuels Y, O'Neil NJ, Trigiante G, Crook T, Hsieh JK et al. iASPP oncoprotein is a key inhibitor of p53 conserved from worm to human. Nat Genet 2003; 33: 162-167.

37. Zhang X, Wang M, Zhou C, Chen S, Wang J. The expression of iASPP in acute leukemias. Leuk Res 2005; 29: 179-183.

38. Chen J, Xie F, Zhang L, Jiang WG. iASPP is over-expressed in human non-small cell lung cancer and regulates the proliferation of lung cancer cells through a p53 associated pathway. BMC Cancer 2010; 10: 694.

39. Liu Z, Zhang X, Huang D, Liu Y, Zhang X, Liu L et al. Elevated expression of IASPP in head and neck squamous cell carcinoma and its clinical significance. Med Oncol 2012; 29: 3381-3388.

40. Zhang B, Xiao HJ, Chen J, Tao X, Cai LH. Inhibitory member of the apoptosis-stimulating protein of p53 (ASPP) family promotes growth and tumorigenesis in human p53-deficient prostate cancer cells. Prostate Cancer Prostatic Dis 2011; 14: 219-224.

41. Notari M, Hu Y, Koch S, Lu M, Ratnayaka I, Zhong S et al. Inhibitor of apoptosis-stimulating protein of p53 (iASPP) prevents senescence and is required for epithelial stratification. Proc Natl Acad Sci USA 2011; 108: 16645-16650.

42. Chikh A, Matin RN, Senatore V, Hufbauer M, Lavery D, Raimondi C et al. iASPP/p63 autoregulatory feedback loop is required for the homeostasis of stratified epithelia. EMBO J 2011; 30: 4261-4273

43. Slee EA, Gillotin S, Bergamaschi D, Royer C, Llanos S, Ali S et al. The N terminus of a novel isoform of human iASPP is required for its cytoplasmic localization. Oncogene 2004; 23: 9007-9016.

44. Taylor RA, Toivanen R, Risbridger GP. Stem cells in prostate cancer: treating the root of the problem. Endocr Relat Cancer 2010; 17: R273-R285.

45. Verhagen AP, Ramaekers FC, Aalders TW, Schaafsma HE, Debruyne FM, Schalken JA. Colocalization of basal and luminal cell-type cytokeratins in human prostate cancer. Cancer Res 1992: 52: 6182-6187.

46. Bonkhoff $\mathrm{H}$, Stein $\mathrm{U}$, Remberger K. Multidirectional differentiation in the normal, hyperplastic, and neoplastic human prostate: simultaneous demonstration of cell-specific epithelial markers. Hum Pathol 1994; 25: 42-46. 
47. Hudson DL, Guy AT, Fry P, O'Hare MJ, Watt FM, Masters JR. Epithelial cell differentiation pathways in the human prostate: identification of intermediate phenotypes by keratin expression. J Histochem Cytochem 2001; 49: 271-278.

48. Xue Y, Smedts F, Debruyne FM, de la Rosette JJ, Schalken JA. Identification of intermediate cell types by keratin expression in the developing human prostate. Prostate 1998; 34: 292-301.

49. Isaacs WB, Carter BS, Ewing CM. Wild-type p53 suppresses growth of human prostate cancer cells containing mutant p53 alleles. Cancer Res 1991; 51: 4716-4720.

50. Prtilo A, Leach FS, Markwalder R, Kappeler A, Burkhard FC, Cecchini MG et al. Tissue microarray analysis of $\mathrm{hMSH} 2$ expression predicts outcome in men with prostate cancer. J Urol 2005; 174: 1814-1818 discussion 1818

51. Grisanzio C, Signoretti S. p63 in prostate biology and pathology. J Cell Biochem 2008; 103 : 1354-1368.

52. Crum CP, McKeon FD. p63 in epithelial survival, germ cell surveillance, and neoplasia. Annu Rev Pathol 2010; 5: 349-371.

53. Signoretti S, Loda M. Defining cell lineages in the prostate epithelium. Cell Cycle 2006; 5 : 138-141.

54. Weinstein MH, Signoretti S, Loda M. Diagnostic utility of immunohistochemical staining for p63, a sensitive marker of prostatic basal cells. Mod Pathol 2002; 15: 1302-1308.

55. Shah RB, Kunju LP, Shen R, LeBlanc M, Zhou M, Rubin MA. Usefulness of basal cell cocktail (34betaE12+p63) in the diagnosis of atypical prostate glandular proliferations. Am J Clin Pathol 2004; 122: 517-523.

56. Wang Y, Hayward S, Cao M, Thayer K, Cunha G. Cell differentiation lineage in the prostate. Differentiation 2001; 68: 270-279.

57. van Leenders GJ, Gage WR, Hicks JL, van Balken B, Aalders TW, Schalken JA et al. Intermediate cells in human prostate epithelium are enriched in proliferative inflammatory atrophy. Am J Pathol 2003; 162: 1529-1537.

58. Carroll DK, Carroll JS, Leong CO, Cheng F, Brown M, Mills AA et al. p63 regulates an adhesion programme and cell survival in epithelial cells. Nat Cell Biol 2006; 8: 551-561.

59. Chang CJ, Chao CH, Xia W, Yang JY, Xiong Y, Li CW et al. p53 regulates epithelialmesenchymal transition and stem cell properties through modulating miRNAs. Nat Cell Biol 2011; 13: 317-323.

60. Cao L, Huang Q, He J, Lu J, Xiong Y. Elevated expression of iASPP correlates with poor prognosis and chemoresistance/radioresistance in FIGO Ib1-lla squamous cell cervical cancer. Cell Tissue Res 2013; 352: 361-369.

61. Jiang L, Siu MK, Wong OG, Tam KF, Lu X, Lam EW et al. IASPP and chemoresistance in ovarian cancers: effects on paclitaxel-mediated mitotic catastrophe. Clin Cancer Res 2011; 17: $6924-6933$.
62. Ananthanarayanan V, Deaton RJ, Yang XJ, Pins MR, Gann PH. Alpha-methylacyl-CoA racemase (AMACR) expression in normal prostatic glands and high-grade prostatic intraepithelial neoplasia (HGPIN): association with diagnosis of prostate cancer. Prostate 2005; 63: 341-346.

63. Braakhuis BJ, Tabor MP, Kummer JA, Leemans CR, Brakenhoff RH. A genetic explanation of Slaughter's concept of field cancerization: evidence and clinical implications. Cancer Res 2003; 63: 1727-1730.

64. Hanson JA, Gillespie JW, Grover A, Tangrea MA, Chuaqui RF, Emmert-Buck MR et al. Gene promoter methylation in prostate tumor-associated stromal cells. J Natl Cancer Inst 2006; 98: 255-261.

65. Mairinger T, Mikuz G, Gschwendtner A. Nuclear chromatin texture analysis of nonmalignant tissue can detect adjacent prostatic adenocarcinoma. Prostate 1999; 41: 12-19.

66. Mehrotra J, Varde S, Wang H, Chiu H, Vargo J, Gray K et al. Quantitative, spatial resolution of the epigenetic field effect in prostate cancer. Prostate 2008; 68: 152-160.

67. Nonn L, Ananthanarayanan V, Gann PH. Evidence for field cancerization of the prostate. Prostate 2009; 69: 1470-1479.

68. Tolonen TT, Tommola S, Jokinen S, Parviainen T, Martikainen PM. Bax and Bcl-2 are focally overexpressed in the normal epithelium of cancerous prostates. Scand J Urol Nephrol 2007; 41: $85-90$.

69. Uetsuki H, Tsunemori H, Taoka R, Haba R, Ishikawa M, Kakehi Y. Expression of a novel biomarker, EPCA, in adenocarcinomas and precancerous lesions in the prostate. J Urol 2005; 174: 514-518.

70. Yu YP, Landsittel D, Jing L, Nelson J, Ren B, Liu L et al. Gene expression alterations in prostate cancer predicting tumor aggression and preceding development of malignancy. J Clin Oncol 2004; 22: 2790-2799.

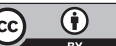

Cell Death and Disease is an open-access journal published by Nature Publishing Group. This work is licensed under a Creative Commons Attribution 3.0 Unported License. The images or other third party material in this article are included in the article's Creative Commons license, unless indicated otherwise in the credit line; if the material is not included under the Creative Commons license, users will need to obtain permission from the license holder to reproduce the material. To view a copy of this license, visit http:// creativecommons.org/licenses/by/3.0/

Supplementary Information accompanies this paper on Cell Death and Disease website (http://www.nature.com/cddis) 